\title{
Hyperlipidaemia alone and in combination with acidosis can increase the incidence and severity of statin-induced myotoxicity
}

Dhiaa A. Taha, ${ }^{a}$ Atheer Zgair, ${ }^{\mathrm{a}, \mathrm{b}}$ Jong Bong Lee, ${ }^{\mathrm{a}}$ Cornelia H. de Moor, ${ }^{\mathrm{c}}$ David A. Barrett, ${ }^{\mathrm{c}}$ Kimberley D. Bruce, ${ }^{\mathrm{d}}$ Mitchell Sungelo, ${ }^{\mathrm{d}}$ Robert H. Eckel, ${ }^{\mathrm{d}}$ and Pavel Gershkovich ${ }^{\mathrm{a}, *}$

a Division of Medicinal Chemistry and Structural Biology, School of Pharmacy, University of Nottingham, Nottingham, UK.

${ }^{\mathrm{b}}$ College of Pharmacy, University of Anbar, Anbar, Iraq.

c Division of Molecular and Cellular Science, School of Pharmacy, University of Nottingham, Nottingham, UK.

d Divisions of Endocrinology, Metabolism and Diabetes, Department of Medicine, University of Colorado Anschutz Medical Campus, Aurora, Colorado, USA.

* Corresponding author: Pavel Gershkovich, School of Pharmacy, Centre for Biomolecular Sciences, University Park, The University of Nottingham, Nottingham, UK, NG7 2RD

Tel: $+44(0) 1158468014$

Fax: +44 (0) 1159513412

Email: pavel.gershkovich@nottingham.ac.uk 


\begin{abstract}
The association of lipophilic statins with plasma lipoproteins in the presence of disturbed acid-base balance can modify the pharmacokinetics and tissue distribution of these drugs, resulting in alteration in their efficacy and toxicity profiles. The purpose of this study is to elucidate the role of hyperlipidaemia alone or in combination with acidosis/alkalosis in the development and potentiation of statin-induced myotoxicity. Statins association with plasma lipoproteins was examined under conditions of physiological and altered $\mathrm{pH}$ levels. The effect of this association on cellular uptake and myotoxicity of statins was also assessed at different $\mathrm{pH}$ levels using $\mathrm{C} 2 \mathrm{C} 12$ cells that overexpress lipoprotein lipase. Lipophilic simvastatin displayed considerable association with the non-polar lipoprotein fractions (triglyceride-rich lipoproteins and Low-density lipoprotein). This association contributed to increased cellular uptake of simvastatin by $\mathrm{C} 2 \mathrm{C} 12$ cells through lipoprotein lipasemediated process, resulting in enhanced muscle toxicity in hyperlipidaemic conditions. Furthermore, a combination of low $\mathrm{pH}$ environment (representing acidosis) and hyperlipidaemia increased the association of simvastatin with plasma lipoproteins causing potentiation of cellular uptake and myotoxicity of this drug. Comorbidities such as hyperlipidaemia, especially when coincident with acidosis, can enhance statin-associated muscle toxicity, and therefore require extra caution by prescribing clinicians. Hydrophilic rather than lipophilic statins could be a preferable choice in this patient population.
\end{abstract}

Keywords: Acidosis, Chylomicrons, Hyperlipidemia, Lipoproteins, Myotoxicity, Statins.

\title{
Chemical compounds studied in this article:
}

Simvastatin lactone (PubChem CID: 54454); Simvastatin hydroxy acid (PubChem CID: 64718); pravastatin lactone (PubChem CID: 9931182); pravastatin hydroxy acid (PubChem CID: 54687). 
Abbreviations: hLPL, human lipoprotein lipase; LDH, lactate dehydrogenase; LDL, low-density lipoprotein; LPDP, lipoprotein-deficient plasma; mLPL, mouse lipoprotein lipase; MTT, thiazolyl blue tetrazolium bromide; MSCV, murine stem cell virus; SV-LDL, simvastatin-loaded low-density lipoprotein; SV-Sol, simvastatin solution; SV-TRL, simvastatin-loaded triglyceride-rich lipoproteins; TRL, triglyceride-rich lipoproteins. 


\section{Introduction}

Statins are essential pharmacotherapy for patients with ischemic heart disease and dyslipidaemia (Perk et al., 2012; Stone et al., 2014). However, these drugs have the potential to cause serious side effects such as muscle-related toxicity and hepatotoxicity. Statins are classified into hydrophilic or lipophilic compounds based on their physicochemical properties and tissue selectivity (Hamelin and Turgeon, 1998; Joshi et al., 1999). These drugs are available either as lactone or hydroxy acid forms. In general, the lactone forms of statins are more lipophilic, and indeed, more myotoxic than the corresponding hydroxy acid forms owing to their lipophilicity (Schirris et al., 2015; Skottheim et al., 2008).

It has been estimated that, in clinical practice, about $10 \%$ of patients receiving high-dosage statin therapy develop statin-induced myotoxicity (Bruckert et al., 2005). The exact mechanism of statin-induced myotoxicity remains largely unclear. Comorbidities including conditions such as hepatic or renal failure, hypothyroidism, and diabetes mellitus are among the most important risk factors that have been shown to predispose patients to statin-induced myotoxicity (Taha et al., 2014). We have previously reported that disturbances in acid-base balance, such as acidosis or alkalosis, could influence the toxicity profile of statins. Acidosis increases the proportion of lipophilic lactone form, promotes accumulation of statins in skeletal muscle cells and enhances statin-induced myotoxicity in vitro (Taha et al., 2016).

Association with plasma lipoproteins has been shown to modify the pharmacokinetics, tissue distribution and pharmacological activity of lipophilic drugs (Wasan and Cassidy, 1998; Yeganeh and McLachlan, 2002). For example, increased association with low-density lipoproteins (LDL) has been linked to higher nephrotoxicity of amphotericin B and cyclosporine (Luke et al., 1992; Wasan and Conklin, 1997).

Transient elevation in triglyceride-rich lipoproteins (TRL), mainly chylomicrons, occurs following the ingestion of a high-fat meal (Gershkovich and Hoffman, 2007). These lipoproteins are the major carriers of lipids in the systemic circulation, and can also serve as potential carriers for lipophilic statins (Simon et al., 1997; Wasan and Cassidy, 1998). Similarly, pathological hyperlipidaemia is associated with elevated levels of some lipoproteins (very low-density lipoprotein 
[VLDL] and LDL). Lipophilic statins can associate with plasma lipoproteins in the general circulation, and this, in turn, can facilitate their delivery to peripheral tissues. Lipoprotein lipase (LPL) present at the surface of the capillary endothelium of cardiac and skeletal muscle and adipose tissue mediates the hydrolysis of triglycerides within the TRL to fatty acids and monoacylglycerol. Released free fatty acids are then transported across cell membranes to the tissues of LPL synthesis and secretion (Wang and Eckel, 2009). This process could be accompanied by an increase in the uptake of lipoprotein-associated lipophilic statins by the skeletal muscle. In addition, LPL also mediates the internalisation of LDL into cells as reported in several studies (Obunike et al., 1994; Rumsey et al., 1992), which could be an additional mechanism of enhanced intracellular accumulation and toxicity of statins in hyperlipidaemic state. Therefore, the administration of lipophilic statins to patients with pathological or postprandial hyperlipidaemia could potentially contribute to enhanced muscle toxicity.

The coincidence of hyperlipidaemia with acidosis could augment the myotoxicity of statins even further. This is because acidosis, as we have previously demonstrated (Taha et al., 2016), increases the proportion of lipophilic lactone form of statins in the general circulation and skeletal muscle. This can contribute to statin-induced muscle toxicity by increasing the association of lactone form with plasma lipoproteins, and increasing the intracellular concentration of statins by LPLmediated mechanism.

Both acidosis and hyperlipidaemia are quite common among statin users. Most patients using statins have abnormal plasma lipoproteins levels. It is common for clinicians to recommend such patients to use unsaturated fat and fatty acids such as olive oil for prevention of cardiovascular and atherosclerotic diseases (Buttar et al., 2005). The use of these oils is associated with transient elevation in plasma TRL, mainly chylomicrons (Jespersen et al., 2001). In addition, many patients on statins have multiple co-morbidities such as diabetes mellitus, cardiovascular and renal diseases. These conditions are risk factors for development of metabolic acidosis (Köse et al., 2014).

To the best of our knowledge, there are no previously reported studies which examined the influence of hyperlipidaemia, or a combination of hyperlipidaemia and acidosis, on the myotoxic potential of statins. Therefore, the aim of this study is to assess the effect of hyperlipidaemia alone 
and in combination with acidosis/alkalosis on development and severity of statin-induced myotoxicity.

\section{Materials and methods}

\subsection{Materials}

Simvastatin lactone (99.3\%) and pravastatin hydroxy acid sodium (99.4\%) were purchased from Kemprotec Ltd (Lancashire, UK). Pravastatin lactone (98\%) and simvastatin hydroxy acid ammonium salt (98.0\%) were obtained from Toronto Research Chemicals Inc (Toronto, Canada). Thiazolyl blue tetrazolium bromide (MTT) was purchased from Alfa Aesar (Lancashire, UK). Dulbecco's modified eagle medium (42430025-DMEM, high glucose, HEPES without sodium pyruvate) was purchased from GIBCO-Invitrogen. Pooled hyperlipidaemic human plasma was obtained from Biological Specialty Corporation (Pennsylvania, USA). LPL activity fluorometric assay kit and total cholesterol and cholesteryl ester colorimetric assay kit were purchased from T/A Source BioScience Ltd (Wiltshire, UK). Microsep ${ }^{\mathrm{TM}}$ advance centrifugal device with Omega ${ }^{\mathrm{TM}}$ membrane was obtained from VWR International Ltd (Leicestershire, UK). Triglyceride reagent, free

glycerol reagent, and glycerol standard were obtained from Sigma-Aldrich (Dorset, UK). Pierce ${ }^{\mathrm{TM}}$ lactate dehydrogenase (LDH) Cytotoxicity Assay kit was purchased from Thermo Fisher Scientific (Loughborough, UK). All other reagents were of high-performance liquid chromatography (HPLC) grade.

\subsection{In silico prediction of statins association with chylomicrons}

A previously reported in silico model was applied to predict the degree of association of simvastatin lactone, simvastatin hydroxy acid, pravastatin lactone and pravastatin hydroxy acid with chylomicrons (Gershkovich et al., 2009). The model relies on physicochemical parameters calculated using ACD/I-Lab (Advanced Chemistry Development Inc.) for each compound (Supplementary Table $1)$. 


\subsection{Association of statins with plasma-derived human chylomicrons}

Chylomicron fractions were obtained from human plasma following induction of transient postprandial hypertriglyceridaemia. The study was approved by the Faculty of Medicine and Health Sciences Research Ethics Committee, Queens Medical Centre, Nottingham University Hospitals (BT12102015 CBS SoP). Three healthy male volunteers (25-35 years old) were recruited for this study after giving informed consents. Participants were instructed not to use any over the counter medication for one-week prior to the study. Following $12 \mathrm{~h}$ overnight fasting, participants had longchain triglyceride-rich breakfast (full English breakfast or olive oil-fried eggs). Three to four hours following the meal [expected time of peak plasma chylomicron levels (Cohn et al., 1988; Cohn et al., 1989)] blood samples $(30 \mathrm{ml})$ were collected and plasma was separated by centrifugation $(800 \mathrm{~g}, 10$ $\left.\min , 15^{\circ} \mathrm{C}\right)$. Chylomicrons were separated from human plasma by density gradient ultracentrifugation using Sorvall ${ }^{\circledR}$ Discovery 100 SE Ultracentrifuge (TH-641 Rotor, $35 \mathrm{~min}, 274,044 \mathrm{~g}, 15^{\circ} \mathrm{C}$ ) as described previously (Gershkovich et al., 2009; Gershkovich and Hoffman, 2005). The top $1 \mathrm{ml}$, white milky layer representing the chylomicron fraction was collected, and triglyceride content was measured using triglyceride colorimetric kit. Chylomicrons emulsion was diluted with PBS to a triglyceride level of $100 \mathrm{mg} / \mathrm{dl}$ and the emulsion was kept at $4{ }^{\circ} \mathrm{C}$ pending association experiments (< $24 \mathrm{~h})$.

The uptake of simvastatin lactone, simvastatin hydroxy acid, pravastatin lactone and pravastatin hydroxy acid by human chylomicrons was evaluated as previously described (Gershkovich et al., 2009; Gershkovich and Hoffman, 2005). All incubation experiments were carried out at physiological $\mathrm{pH} 7.4$ in addition to $\mathrm{pH}$ levels that correspond to acidosis ( $\mathrm{pH} \mathrm{6.8)} \mathrm{and} \mathrm{alkalosis} \mathrm{(} \mathrm{pH} 7.8$ ) as describe previously (Taha et al., 2016). The selection of this range was based on extreme but clinically relevant disturbances in acid-base balance that are encountered in patients with long-term diuretics use (Tripathy, 2009), prolonged vomiting (Galla, 2000), diabetic ketoacidosis (Wathen and Starkey, 1986), lactic acidosis (Winocour et al., 1989), renal tubular acidosis (Kraut and Kurtz, 2005), hypovolemic shock (Zimmer, 2014), and ethylene glycol intoxication (Lundgaard, 2009). It should be noted that significant effects of milder plasma $\mathrm{pH}$ alterations on statin inter-conversion between lactone and hydroxy acid forms were also reported in our previous works (Taha et al., 2016). 
Stock solutions of four statins $(350 \mu \mathrm{M})$ were prepared in propylene glycol and an appropriate volume of each solution was added to $1 \mathrm{ml}$ of human chylomicron emulsions of different $\mathrm{pH}$ to achieve a final concentration of $1.75 \mu \mathrm{M}$. Statins were incubated with chylomicrons at $37^{\circ} \mathrm{C}$ for $1 \mathrm{~h}$ with constant mixing. Following incubation, statin-loaded chylomicron particles were separated by density gradient ultracentrifugation (Sorvall ${ }^{\circledR}$ Discovery 100 SE Ultracentrifuge; TH-641 Rotor, 35 $\left.\min , 274,044 \mathrm{~g}, 15^{\circ} \mathrm{C}\right)$. The top $1 \mathrm{ml}$ was collected and kept at $-80^{\circ} \mathrm{C}$ until analysis. The concentrations of statins in chylomicron fraction were determined by liquid chromatography-tandem mass spectrometry (LC-MS/MS) method as described previously (Taha et al., 2016).

\subsection{Effect of hyperlipidaemia alone or in combination with acidosis/alkalosis on simvastatin association with plasma lipoproteins}

Both normolipidaemic (total triglyceride $63.0 \pm 2.9 \mathrm{mg} / \mathrm{dl}$; cholesterol $134.7 \pm 8.9 \mathrm{mg} / \mathrm{dl}$ ) and hyperlipidaemic (total triglyceride $448.0 \pm 12.1 \mathrm{mg} / \mathrm{dl}$; cholesterol $348.5 \pm 15.5 \mathrm{mg} / \mathrm{dl}$ ) plasmas were used for the evaluation of simvastatin association with plasma lipoproteins. The $\mathrm{pH}$ of plasma samples was adjusted to achieve physiological pH 7.4, $\mathrm{pH} 6.8$ (acidosis) or $\mathrm{pH} 7.8$ (alkalosis), as described previously (Taha et al., 2016).

An appropriate volume of simvastatin lactone stock solution was added to $3 \mathrm{ml}$ of normolipidaemic or hyperlipidaemic human plasma of defined $\mathrm{pH}$ to achieve final simvastatin concentration of $2 \mu \mathrm{g} / \mathrm{ml}$. Samples were incubated at $37^{\circ} \mathrm{C}$ for $1 \mathrm{~h}$ and lipoprotein fractions were separated by density gradient ultracentrifugation at $274,044 \mathrm{~g}$ for $18 \mathrm{~h}$, as described previously (Redgrave et al., 1975). The concentrations of simvastatin lactone and hydroxy acid forms found in individual lipoprotein fractions were determined by LC-MS/MS (Taha et al., 2016). The total triglyceride and cholesterol levels of hyperlipidaemic plasma, normolipidaemic plasma and individual lipoprotein fractions were determined by enzymatic methods using commercially available kits. 


\subsection{Effect of hyperlipidaemia alone or in combination with acidosis/alkalosis on cellular uptake of}

\section{lipophilic statin}

$\mathrm{C} 2 \mathrm{C} 12$ cells that overexpress mouse lipoprotein lipase (mLPL) or human lipoprotein lipase (hLPL) were used in these studies. Cells transfected with empty vector were used as control. mLPL and hLPL were cloned into murine stem cell virus (MSCV) mammalian expression vector. To produce retrovirus for stable overexpression of hLPL and mLPL, $6 \mu \mathrm{g}$ of each plasmid (mLPL, hLPL, and the empty MSCV vector) was combined with a transformation mixture containing $3 \mu \mathrm{g}$ pCL-Eco packaging plasmid, $2 \mu \mathrm{g}$ VSVG pseudotyping plasmid, and $33 \mu 1$ Lipofectamine 2000 (Invitrogen) in $1 \mathrm{ml}$ Opti-MEM (Invitrogen). The transformation cocktails were added to Phoenix 293T retroviral packaging cells grown to $\sim 85 \%$ confluence. Virus-containing supernatant was then harvested from the packaging cells $48 \mathrm{~h}$ following transfection. $\mathrm{C} 2 \mathrm{C} 12$ cells at $\mathrm{P} 2$ were then grown to $30 \%$ confluence and incubated with the virus-containing supernatant along with $10 \mu \mathrm{g} / \mathrm{ml}$ polybrene. The cells were incubated with the virus for $24 \mathrm{~h}$ followed by a medium change and a $24 \mathrm{~h}$ recovery period.

$\mathrm{C} 2 \mathrm{C} 12$ cells were cultured in a humidified environment of $5 \% \mathrm{CO}_{2}$ at $37^{\circ} \mathrm{C}$ and maintained sub-confluent (70-80\%) by growing in DMEM medium supplemented with $10 \%$ fetal bovine serum, 1\% L-glutamine and 1\% penicillin-streptomycin antibiotic mixture. Myogenic differentiation was induced by growing the cells in differentiation medium containing $2 \%$ horse serum. The cells were cultured over a period of 4 to 6 days to allow complete differentiation and the medium was replaced every 24 h (Masilamani et al., 2014).

The effect of hyperlipidaemia alone and in combination with acidosis/alkalosis on cellular uptake of simvastatin was tested by incubating $\mathrm{C} 2 \mathrm{C} 12$ cells with simvastatin-loaded lipoprotein fractions at $\mathrm{pH}$ relevant to physiological conditions, acidosis, and alkalosis. Simvastatin-loaded lipoprotein fractions were obtained by incubating the drug with hyperlipidaemic human plasma of different $\mathrm{pH}$. An appropriate volume of simvastatin lactone stock solution prepared in propylene glycol $(9 \mathrm{mg} / \mathrm{ml})$ was added to hyperlipidaemic human plasma of defined $\mathrm{pH}(6.8,7.4$ or 7.8$)$ to achieve a final concentration of $90 \mu \mathrm{g} / \mathrm{ml}$. Samples were incubated at $37^{\circ} \mathrm{C}$ for $1 \mathrm{~h}$. Lipoprotein fractions were then separated by density gradient ultracentrifugation as described above. After separation, individual lipoprotein fractions were transferred into Microsep ${ }^{\mathrm{TM}}$ Advance Centrifugal 
Device with Omega ${ }^{\mathrm{TM}}$ membrane for removal of potassium bromide salt used in lipoproteins separation. Aliquots were used to determine the concentration of simvastatin in individual lipoprotein fractions by LC-MS/MS. The remaining volume of lipoprotein fractions was used to perform the uptake study by undifferentiated and differentiated C2C12 cells that overexpress mLPL, hLPL, and control cells transfected with empty vector. Cells were cultured in $10 \mathrm{~cm}$ dishes at a density of $2 \times 10^{5} / \mathrm{ml}$ and allowed to attach for $24 \mathrm{~h}$ or to differentiate for 4 days by switching to differentiation medium containing $2 \%$ horse serum. Before starting the uptake study, the medium was replaced with a fresh medium of different $\mathrm{pH}$ and the cells were allowed to equilibrate for 10 min. The uptake studies were initiated by applying simvastatin-loaded lipoprotein fractions (simvastatin-loaded triglyceride-rich lipoproteins [SV-TRL] or simvastatin-loaded low-density lipoprotein [SV-LDL]) to the cells and the cells were incubated for $3 \mathrm{~h}$ at $37^{\circ} \mathrm{C}$ and $5 \% \mathrm{CO}_{2}$. Control cells were treated with a similar concentration of simvastatin applied as a solution (SV-Sol) directly on the cells without lipoprotein fractions. Simvastatin uptake was terminated by suctioning off the DMEM containing the lipoprotein fractions and the cells were harvested by trypsinization and resuspended in $200 \mu 1$ phosphate buffer saline (PBS, pH 7.4). The intracellular concentrations of both simvastatin lactone and the hydroxy acid form were determined in cell suspension using LC-MS/MS, and the results were corrected for cellular protein contents as described previously (Taha et al., 2016). LPL enzyme activity was determined using commercially available kit by following the manufacturer's instructions.

\subsection{Effect of hyperlipidaemia alone or in combination with acidosis/alkalosis on cytotoxicity of} simvastatin

The effect of simvastatin association with plasma lipoproteins on the viability of $\mathrm{C} 2 \mathrm{C} 12$ cells was evaluated by MTT and LDH cytotoxicity assays. Undifferentiated and differentiated C2C12 cells that overexpress mLPL or hLPL, and control cells were treated either with simvastatin-loaded lipoproteins factions or with simvastatin applied directly in solution at concentrations identical to those achieved within the lipoprotein fractions. The incubation was performed in culture medium of physiological $\mathrm{pH}$ 7.4. In order to assess the combined effect of elevated plasma lipoprotein levels and 
medium $\mathrm{pH}$ alteration on the cytotoxicity of simvastatin, $\mathrm{C} 2 \mathrm{C} 12$ cells were also incubated in culture medium of modified $\mathrm{pH}(6.8$ and 7.8).

For MTT assay, cells were cultured at a density of 4,000 cells/ well in 96-well plates and allowed to attach for $24 \mathrm{~h}$ or to differentiate for 4 days. Before starting the treatment, the medium was replaced by a fresh one of defined $\mathrm{pH}$ and the cells were allowed to equilibrate for $10 \mathrm{~min}$. $\mathrm{C} 2 \mathrm{C} 12$ cells were exposed to different concentrations of simvastatin either loaded into lipoprotein fractions (SV-TRL or SV-LDL) or applied directly in solution for $72 \mathrm{~h}$, and the metabolic activity of the cells was measured using the MTT assay. Control cells were treated with blank lipoprotein fractions without simvastatin. Results were expressed as percentage of the control and the half-maximal inhibitory concentrations $\left(\mathrm{IC}_{50}\right)$ values were calculated using Prism 6 (GraphPad Software $\mathrm{Inc}$ ).

Membrane integrity of $\mathrm{C} 2 \mathrm{C} 12$ cells was assessed by means of LDH assay. The test was performed at the final simvastatin concentrations that were obtained in the lipoprotein fractions after desalting process. Cells were cultured and treated as described above. Undifferentiated cells were treated for $72 \mathrm{~h}$, whereas differentiated cells were maintained for $24 \mathrm{~h}$ and LDH assay was performed according to manufacturer's instructions.

\subsection{Statistical analysis}

Data were expressed as mean \pm standard error (SE). Statistical differences between groups were determined by one-way or two-way ANOVA, followed by Tukey's or Fisher's least significant difference (LSD) post hoc tests, as appropriate using Prism 6 (GraphPad Software Inc). Pearson's correlation coefficient (r) was used to describe the relationship between the amount of simvastatinassociated with plasma lipoproteins and the triglyceride or cholesterol contents of individual lipoprotein fractions using IBM SPSS statistics 22.0. A $p$-value of less than 0.05 was considered to be statistically significant. 


\section{Results}

\subsection{In silico prediction of statins association with chylomicrons}

The predictive values of statins association with chylomicrons obtained using the in silico model are presented in Supplementary Table 1. Simvastatin hydroxy acid, pravastatin lactone and pravastatin hydroxy acid showed no predicted association with chylomicrons. Simvastatin lactone was the only form that showed a considerable predicted affinity to chylomicrons $(9.08 \%)$.

\subsection{Association of statins with plasma-derived isolated chylomicrons}

Similar to in silico prediction, simvastatin hydroxy acid, pravastatin lactone and pravastatin hydroxy acid showed no association with chylomicrons ex vivo. These statins have not been selected for subsequent studies because of the lack of association of these compounds with chylomicrons (as demonstrated by the in silico and ex vivo models over different $\mathrm{pH}$ levels), as well as low cytotoxicity observed with these statins as described in our previous study (despite the fact that $\mathrm{pH}$ affects the conversion of these statins between the hydroxy acid and lactone forms) (Taha et al., 2016). The results of association of simvastatin lactone with plasma-derived isolated chylomicrons are summarised in Fig. 1. At physiological $\mathrm{pH}$, the association of simvastatin with chylomicrons was found to be $18.5 \%$. When association was tested at different $\mathrm{pH}$ levels, significant differences were found at alkaline $\mathrm{pH}$. The association value was the lowest in alkaline condition (14.2\%) while neutral $\mathrm{pH}$ and acidic $\mathrm{pH}$ resulted in higher association values (18.5\% and $19.3 \%$, respectively). No simvastatin lactone was detected in the upper $1 \mathrm{ml}$ layer of the ultracentrifuge tube (corresponding to chylomicron fraction) in the control (PBS) samples.

\subsection{Effect of hyperlipidaemia alone or in combination with acidosis/alkalosis on simvastatin association with plasma lipoproteins}

The distribution of simvastatin lactone into different lipoprotein fractions from hyperlipidaemic and normolipidaemic human plasma is presented in Fig. 2. Simvastatin lactone showed considerably higher association with the non-polar lipoproteins fractions [TRL (including both chylomicrons and VLDL) and LDL] extracted from hyperlipidaemic plasma, compared to its association with 
lipoproteins from normolipidaemic plasma. On the other hand, more simvastatin associated with highdensity lipoprotein (HDL) of normolipidaemic plasma compared to hyperlipidaemic plasma.

To investigate the factors influencing simvastatin association with plasma lipoproteins, cholesterol and triglyceride levels were determined in each lipoprotein fraction from hyperlipidaemic and normolipidaemic plasma samples (Supplementary Fig. 1 and 2, respectively). In addition, the correlations between the amount of simvastatin recovered in individual lipoprotein fractions and the amount of triglyceride and cholesterol present in each fraction were examined (Supplementary Fig. 3 and 4). Positive correlations $(p<0.01)$ were observed between the amount of triglyceride or cholesterol and the amount of simvastatin-associated with TRL and LDL. On the other hand, negative correlations $(p<0.01)$ were found between the amounts of simvastatin recovered in HDL and triglyceride or cholesterol contents of this fraction. As expected, the correlations between the triglyceride or cholesterol contents of lipoprotein-deficient plasma (LPDP) fraction and the amount of simvastatin recovered within this fraction were non-significant $(p>0.05)$.

Overall, simvastatin association with different plasma lipoproteins in hyperlipidaemic plasma was greater at acidic $\mathrm{pH}$ compared to physiological and alkaline $\mathrm{pH}$. At acidic $\mathrm{pH}$, more than $50 \%$ of simvastatin distributed to different lipoprotein fractions in hyperlipidaemia plasma ( $20 \%$ in TRL, $20 \%$ in LDL, and 16\% in HDL). The remaining simvastatin (less than 50\%) appeared in the LPDP fraction. However, at physiological and alkaline $\mathrm{pH}$, most simvastatin was recovered in the LPDP fraction (Fig. 2).

Measuring the concentrations of simvastatin lactone and the corresponding hydroxy acid within each lipoprotein fraction provided a picture of the effect of plasma $\mathrm{pH}$ alteration on simvastatin distribution into different lipoprotein fractions (Supplementary Fig. 5 and 6). At acidic pH, the majority of simvastatin recovered in lipoprotein fractions was in the lipophilic lactone form. As the $\mathrm{pH}$ increases, more simvastatin lactone starts to convert to the more hydrophilic hydroxy acid form, resulting in simvastatin redistribution to the more polar LPDP fraction. 


\subsection{Effect of hyperlipidaemia alone or in combination with acidosis/alkalosis on cellular uptake of}

\section{lipophilic statin}

To examine the effect of plasma lipoprotein association on cellular uptake of simvastatin, C2C12 cells were incubated with simvastatin loaded into lipoprotein fractions (TRL or LDL) or applied directly as a solution. In addition to physiological $\mathrm{pH}$, uptake study was also conducted at $\mathrm{pH}$ corresponding to acidosis and alkalosis to elucidate the role of hyperlipidaemia and acid-base imbalance on cellular uptake of simvastatin. Figure 3 shows the total simvastatin (lactone and hydroxy acid forms combined) taken up by $\mathrm{C} 2 \mathrm{C} 12$ cells that overexpress mLPL, hLPL, or control cells following treatment with simvastatin-loaded TRL. The same amounts of simvastatin were recovered in undifferentiated cells that have low endogenous LPL expression ability following treatment either with TRL bound simvastatin or free simvastatin in solution. On the other hand, higher simvastatin uptake was observed in undifferentiated cells that overexpress mLPL or hLPL upon treatment with simvastatin-preloaded TRL fractions compared to simvastatin in solution (Fig. 3).

Results of simvastatin uptake by $\mathrm{C} 2 \mathrm{C} 12$ cells treated with simvastatin-loaded LDL are shown in Fig. 4. Undifferentiated C2C12 cells that overexpress mLPL or hLPL showed higher simvastatin uptake when treated with simvastatin-loaded LDL compared to their treatment with simvastatin solution (Fig. 4). No significant differences in simvastatin uptake was detected in control undifferentiated $\mathrm{C} 2 \mathrm{C} 12$ cells following treatment with either simvastatin-loaded LDL or simvastatin applied directly in solution at physiological and alkaline $\mathrm{pH}$. However, more simvastatin was found in these cells under acidic conditions when treated with simvastatin solution compared to simvastatinloaded LDL (Fig. 4). Overall, higher cellular uptake was observed when undifferentiated cells were treated with simvastatin-loaded LDL compared to their treatment with simvastatin-loaded TRL (Fig. 3 and 4).

Differentiated C2C12 cells that overexpress mLPL or hLPL showed higher simvastatin uptake upon treatment with simvastatin-loaded lipoprotein fractions compared to free simvastatin solution. It is worth noting that differentiated control cells (transfected with empty vector) also showed higher simvastatin uptake when treated with simvastatin-loaded LDL compared to undifferentiated cells (Fig. 4). 
A remarkable point is that the amounts of simvastatin found in differentiated cells were severalfold higher than in undifferentiated cells following treatment with simvastatin associated with lipoprotein fractions (Supplementary Fig. 7 and 8). The data also show that maintaining both undifferentiated and differentiated cells in acidic medium further increases the cellular uptake of simvastatin whether it is bound to lipoprotein fractions or applied as free simvastatin in solution (Fig. 3 and 4$)$.

To illustrate the role of LPL in the cellular uptake of simvastatin-loaded lipoprotein particles, the activity of the enzyme was measured in the different cell types used in our studies. The activity was found to be almost three- and two-fold higher in undifferentiated $\mathrm{C} 2 \mathrm{C} 12$ cells that overexpress mLPL or hLPL compared to control cells, respectively. On the other hand, differentiated C2C12 cells that overexpress mLPL showed higher enzyme activity compared to those expressing hLPL or control cells (Fig. 5). In addition, differentiated mLPL transfected cells showed 1.5 -fold higher LPL activity compared to undifferentiated cells (Supplementary Fig. 9).

\subsection{Effect of hyperlipidaemia alone or in combination with acidosis/alkalosis on cytotoxicity of simvastatin}

The effects of simvastatin association with plasma lipoproteins on the mitochondrial activity of $\mathrm{C} 2 \mathrm{C} 12$ cells were assessed by MTT assay using simvastatin-loaded lipoprotein fractions. The incubations were performed at physiological $\mathrm{pH}$, in addition to $\mathrm{pH}$ levels corresponding to acidosis and alkalosis, in order to further explore the combined effects of hyperlipidaemia and $\mathrm{pH}$ alteration on the viability of muscle cells. Results from MTT assay over different concentrations of simvastatinloaded TRL and LDL fractions are shown in Fig. 6 and 7, respectively. To provide a comparison between different treatment conditions, the $\mathrm{IC}_{50}$ were calculated, when applicable, for each growth inhibition-dose curve. The results of cell viability assay showed higher cytotoxicity when $\mathrm{C} 2 \mathrm{C} 12$ cells were treated with simvastatin-loaded lipoprotein fractions compared to cells treated with simvastatin solution. Furthermore, the inhibitory effect of simvastatin-loaded lipoprotein fractions on cell viability was more pronounced with cells that overexpress mLPL compared to those expressing hLPL or control cells. Cells that overexpress hLPL showed moderate response to simvastatin-loaded 
lipoprotein therapy and the $\mathrm{IC}_{50}$ values were in between those overexpressing $\mathrm{mLPL}$ or control cells. Both undifferentiated and differentiated cells were found to be more sensitive to simvastatin when applied loaded into LDL compared to simvastatin-loaded TRL fractions (Fig. 6 and 7).

Treating undifferentiated or differentiated $\mathrm{C} 2 \mathrm{C} 12$ cells with simvastatin in culture medium of acidic $\mathrm{pH}$ resulted in significant reduction in cell viability whether the cells were treated with simvastatin-loaded lipoprotein fractions or free simvastatin in solution. On the other hand, no significant reduction in cell viability was observed for cells maintained in alkaline culture medium following treatment with simvastatin-loaded lipoprotein fractions or simvastatin solution. At this alkaline $\mathrm{pH}$ (7.8), the viability of the cells remained above $50 \%$ even after treatment with the highest dose of simvastatin and therefore it was not possible to calculate the $\mathrm{IC}_{50}$ values under this treatment condition (Fig. 6 and 7).

Results of LDH release from undifferentiated and differentiated $\mathrm{C} 2 \mathrm{C} 12$ cells are shown in Fig. 8. Overall, more LDH was released from these cells when treated with simvastatin-loaded lipoprotein fractions compared to cells treated with simvastatin solution. The higher LPL enzyme activity in undifferentiated cells that overexpress mLPL produced an additional increase in LDH release when treated with simvastatin-loaded TRL. Moreover, treating these cells with simvastatin-loaded LDL resulted in greater LDH release compared to cells that have low endogenous enzyme activity. Higher LDH release was observed for cells maintained in acidic culture medium compared to neutral and alkaline medium following exposure to simvastatin solution or simvastatin-loaded lipoprotein fractions. 


\section{Discussion}

Certain comorbidities such as hepatic or renal failure, hypothyroidism, and diabetes mellitus have been suggested to affect the occurrence and severity of statin-associated muscle symptoms (Chatzizisis et al., 2010; Reiner, 2014). The current study describes the role of hyperlipidaemia, a primary disorder for which statins are considered as first choice therapy, in development and potentiation of statin-induced myotoxicity. An increased association of lipophilic drugs with plasma lipoproteins in hyperlipidaemic patients can affect drug distribution and toxicity profile (Wasan and Cassidy, 1998; Yeganeh and McLachlan, 2002). Since acidosis is known to enhance the lipophilicity of statins (Taha et al., 2016), it is possible that the coexistence of acidosis with hyperlipidaemia could further augment the myotoxicity of statins. To the best of our knowledge, this is the first work that elucidates the influence of pathological or postprandial hyperlipidaemia alone or in combination with acidosis/alkalosis on the development and severity of simvastatin-induced myotoxicity.

\subsection{Association of statins with plasma-derived isolated chylomicrons}

Results from in silico model for prediction of drug uptake by plasma chylomicrons indicate that physicochemical properties of statins highly influence their uptake by plasma lipoproteins. Simvastatin lactone (lipophilic statin) with a high $\log \mathrm{D}_{7.4}$ and low polar surface area showed the highest association with chylomicrons.

When the association of simvastatin lactone was assessed with human chylomicrons, a significant $\mathrm{pH}-$ dependent trend was observed. Alkaline $\mathrm{pH}$ resulted in the lowest association (Fig. 1), suggesting that in the pathophysiological condition of alkalosis less simvastatin would be able to associate with plasma lipoproteins. On the other hand, acidosis can result in more simvastatin becoming associated with plasma lipoproteins.

A greater percentage of simvastatin lactone is expected to associate with chylomicrons upon entrance into the blood stream especially in the presence of postprandial or pathological hyperlipidaemia which is often associated with elevated levels of TRL. Such association raises the possibility of altered therapeutic and toxic response to lipophilic statins. 


\subsection{Effect of hyperlipidaemia alone or in combination with acidosis/alkalosis on simvastatin}

association with plasma lipoproteins

Hyperlipidaemia can affect the pharmacokinetics and pharmacodynamics of drugs (Procyshyn et al., 2003). This may occur through due to a shift in binding of lipophilic drug from plasma proteins to the non-polar lipoprotein fractions such as TRL and LDL (Hamdy and Brocks, 2011).

The concentrations of plasma lipoproteins in the blood can vary significantly among individuals as a function of diet or disease states. This variability could have significant implications on the fate of drugs that associate with plasma lipoproteins. In the present study, simvastatin has been shown to associate with different lipoprotein fractions in hyperlipidaemic and normolipidaemic plasma, and more significant association with lipoprotein fractions obtained from hyperlipidaemic plasma (Fig. 2). Several factors have been suggested to influence the extent of drug association with plasma lipoproteins. Some of these factors are linked to the molecular nature of the compounds such as drug lipophilicity. Other factors are related to the nature of lipoproteins such as size, total lipid contents or apolipoprotein components of lipoprotein fractions (Wasan et al., 2008). In the present study, significant positive correlations were observed between the triglyceride and cholesterol contents of lipoprotein fractions (TRL and LDL) and the degree of simvastatin association with these fractions (Supplementary Fig. 3 and 4).

More simvastatin has been shown to associate with plasma lipoproteins at acidic $\mathrm{pH}$ compared to physiological and alkaline $\mathrm{pH}$ (Fig. 2). The higher association at acidic $\mathrm{pH}$ occurs as a result of simvastatin's increased lipophilicity as majority of simvastatin molecules remain in the highly lipophilic lactone form at low pH (Supplementary Fig. 5 and 6).

\subsection{Effect of hyperlipidaemia with or without acidosis and alkalosis on cellular uptake of lipophilic statin}

Drug binding to plasma lipoproteins has been suggested to affect the blood-tissue partitioning of lipophilic compounds, resulting in alterations in the pharmacological activity and/or potential toxicity of these molecules (Wasan et al., 2008). In this study, the association of simvastatin with plasma lipoproteins, particularly TRL and LDL, has enhanced the cellular uptake of lipophilic statin 
by $\mathrm{C} 2 \mathrm{C} 12$ cells (Fig. 3 and 4). The partitioning of lipophilic statin from plasma lipoproteins to the cells seems to be mediated by LPL. This enzyme is responsible for the intravascular hydrolysis of triglycerides within lipoproteins into fatty acids and monoacylglycerol. It also regulates the cellular uptake of fatty acids and cholesterol and controls the transport and internalisation of lipoprotein particles by peripheral tissues by enhancing their binding to lipoprotein receptors (Obunike et al., 1994; Rumsey et al., 1992). Statin uptake from plasma lipoproteins could be of a particular importance when skeletal muscle tissue highly expresses LPL. Several conditions have been reported to increase LPL expression in human skeletal muscle cells, such as chronic exercise, fibrate therapy and fasting (Yokoyama et al., 2007). These conditions could increase the risk of statin-induced myopathy by increasing the muscle uptake of simvastatin via the above-mentioned mechanism. Indeed, the majority of professional athletes were found to be intolerant to most of the available statins (Sinzinger and O'Grady, 2004). This group of population is known to have increased muscle LPL expression (Herbert et al., 1984).

The extent of simvastatin uptake by $\mathrm{C} 2 \mathrm{C} 12$ cells was partially proportional to the activity of LPL in these cells. More simvastatin was taken up by cells that have higher LPL activity (mLPL $\approx$ hLPL > empty) (Fig. 3 and 4). Our results are in agreement with previous studies that demonstrated an increase in the uptake of lipoprotein-associated compounds by tissues in the presence of LPL (Nakamura et al., 1998; Sattler et al., 1996; Traber et al., 1985). The enhancement of simvastatin uptake by $\mathrm{C} 2 \mathrm{C} 12$ cells that have high LPL activity could be attributed to the higher triglyceride hydrolysis rates (Traber et al., 1985), and the bridging function of the enzyme between lipoproteindrug complex and muscle cells (Sattler et al., 1996).

More simvastatin was found to be taken up by $\mathrm{C} 2 \mathrm{C} 12$ cells when treated with simvastatinloaded LDL compared to simvastatin-loaded TRL. This process could be of clinical significance since statin therapy has been shown to induce upregulation of LDL receptors in the skeletal muscle cells (Yokoyama et al., 2007), resulting in an increased uptake of simvastatin-associated LDL by muscle cells via LPL-mediated mechanism.

The cellular uptake of simvastatin by $\mathrm{C} 2 \mathrm{C} 12$ cells was found to be strongly affected by the $\mathrm{pH}$ levels of the culture medium. Higher simvastatin uptake was observed at acidic $\mathrm{pH}$ compared to 
physiological and alkaline $\mathrm{pH}$. These results are in agreement with our previous observations that showed higher cellular uptake of statins at acidic conditions compared to physiological and alkaline environment (Taha et al., 2016).

\subsection{Effect of hyperlipidaemia with or without acidosis and alkalosis on cytotoxicity of simvastatin}

In the present study, the higher cytotoxicity of simvastatin observed in the presence of elevated plasma lipoprotein levels are linked to drug association with TRL and LDL. These lipoprotein fractions can serve as carriers for lipophilic statins and have been shown to increase simvastatin uptake by muscle cells (Fig. 3 and 4).

In accordance with the uptake studies, the cytotoxicity profile of simvastatin-lipoprotein complex in $\mathrm{C} 2 \mathrm{C} 12$ cells was found to be proportional to the activity of LPL in these cells. Higher cytotoxicity was observed in cells that have higher LPL enzyme activity (mLPL $>$ hLPL $>$ empty) (Fig. 6 and 7). The effect of simvastatin association with plasma lipoproteins on the cytotoxicity was further augmented when the skeletal muscle cells were maintained at acidic $\mathrm{pH}$ compared to physiological and alkaline $\mathrm{pH}$. The higher cytotoxicity of simvastatin under acidic conditions could be attributed to the greater proportions of the lactone form of simvastatin that are associated with plasma lipoprotein fractions. This lipophilic lactone from has higher ability to cross the cell membranes of muscle cells and achieve high intracellular concentrations. On the other hand, the low cytotoxicity observed under alkaline conditions is due to the low levels of the lactone form recovered within the lipoprotein fractions under these conditions, resulting in lower intracellular concentrations of simvastatin (Taha et al., 2016). 


\section{Conclusions}

This study demonstrated that hyperlipidaemia enhanced the association of simvastatin with the non-polar plasma lipoprotein fractions such as TRL and LDL. This association contributed to increased cellular uptake of this lipophilic statin by skeletal muscle cells resulting in a high local intracellular concentration of simvastatin through LPL-mediated process. Moreover, the high intracellular concentrations of simvastatin induced significantly higher myotoxicity compared to normolipidaemic conditions. The coincidence of acidosis with hyperlipidaemia further augmented the myotoxicity of this lipophilic statin. Acidic $\mathrm{pH}$ enhanced the association of simvastatin with plasma lipoproteins by minimising the conversion of lipophilic lactone form to the hydrophilic hydroxy acid. As a result, the intracellular concentrations of simvastatin in muscle cell line, as well as myotoxicity were increased. The potential clinical significance of these results is that hyperlipidaemia, especially when combined with acidosis, requires extra caution and monitoring by clinicians who should follow a conservative approach when prescribing lipophilic statins to these patients. Hydrophilic rather than lipophilic statins could be a preferable choice in patients that are prone to hyperlipidaemia with or without acidosis.

\section{Acknowledgments}

This work is supported by the higher committee for education development (HCED) in Iraq.

\section{Declarations of interest}

The authors declare that they have no conflict of interest. 


\section{References}

Bruckert, E., Hayem, G., Dejager, S., Yau, C., Begaud, B., 2005. Mild to moderate muscular symptoms with high-dosage statin therapy in hyperlipidemic patients-the PRIMO study. Cardiovasc. Drugs Ther. 19, 403-414.

Buttar, H.S., Li, T., Ravi, N., 2005. Prevention of cardiovascular diseases: Role of exercise, dietary interventions, obesity and smoking cessation. Exp. Clin. Cardiol. 10, 229-249.

Chatzizisis, Y.S., Koskinas, K.C., Misirli, G., Vaklavas, C., Hatzitolios, A., Giannoglou, G.D., 2010. Risk factors and drug interactions predisposing to statin-induced myopathy: implications for risk assessment, prevention and treatment. Drug Saf. 33, 171-187.

Cohn, J.S., Mcnamara, J., Cohn, S., Ordovas, J., Schaefer, E., 1988. Postprandial plasma lipoprotein changes in human subjects of different ages. J. Lipid Res. 29, 469-479.

Cohn, J.S., Mcnamara, J.R., Krasinski, S.D., Russell, R.M., Schaefer, E.J., 1989. Role of triglyceride-rich lipoproteins from the liver and intestine in the etiology of postprandial peaks in plasma triglyceride concentration. Metabolism. 38, 484-490.

Galla, J.H., 2000. Metabolic alkalosis. J. Am. Soc. Nephrol. 11, 369-375.

Gershkovich, P., Fanous, J., Qadri, B., Yacovan, A., Amselem, S., Hoffman, A., 2009. The role of molecular physicochemical properties and apolipoproteins in association of drugs with triglyceride-rich lipoproteins: in-silico prediction of uptake by chylomicrons. J. Pharm. Pharmacol. 61, 31-39.

Gershkovich, P., Hoffman, A., 2005. Uptake of lipophilic drugs by plasma derived isolated chylomicrons: Linear correlation with intestinal lymphatic bioavailability. Eur. J. Pharm. Sci. 26, 394-404.

Gershkovich, P., Hoffman, A., 2007. Effect of a high-fat meal on absorption and disposition of lipophilic compounds: the importance of degree of association with triglyceride-rich lipoproteins. Eur. J. Pharm. Sci. 32, 24-32.

Hamdy, D.A., Brocks, D.R., 2011. The effect of increased lipoprotein levels on the pharmacokinetics of ketoconazole enantiomers in the rat. Xenobiotica. 41, 137-143.

Hamelin, B.A., Turgeon, J., 1998. Hydrophilicity/lipophilicity: relevance for the pharmacology and clinical effects of HMG-CoA reductase inhibitors. Trends Pharmacol. Sci. 19, 26-37.

Herbert, P.N., Bernier, D.N., Cullinane, E.M., Edelstein, L., Kantor, M.A., Thompson, P.D., 1984. High-density lipoprotein metabolism in runners and sedentary men. JAMA. 252, 1034-1037. 
Jespersen, L., Jakobsen, M., Hasseldam, H., Marckmann, P., 2001. The effect of dietary oils on blood lipids and the risk of ischemic heart disease with special emphasis on olive oil. A literature review. Ugeskr. Laeger. 163, 4736-4740.

Joshi, H.N., Fakes, M.G., Serajuddin, A., 1999. Differentiation of 3-hydroxy-3-methylglutaryl-coenzyme A reductase inhibitors by their relative lipophilicity. Pharm. Pharmacol. Commun. 5, 269-271.

Köse, A., Armagan, E., Öner, N., Köksal, Ö., Mert, D.K., Özdemir, F., Aydin, S.A., 2014. Acid-base disorders in the emergency department: incidence, etiologies and outcomes. JAEM. 13, 4-9.

Kraut, J.A., Kurtz, I., 2005. Metabolic acidosis of CKD: diagnosis, clinical characteristics, and treatment. Am. J. Kidney Dis. 45, 978-993.

Luke, D.R., Brunner, L.J., Lopez-Berestein, G., Yau, J.C., 1992. Pharmacokinetics of cyclosporine in bone marrow transplantation: Longitudinal characterization of drug in lipoprotein fractions. J. Pharm. Sci. $81,208-211$

Lundgaard, P., 2009. Extreme metabolic acidosis after presumed intoxication with ethylene glycol. Ugeskr. laeger. 171, 1866-1867.

Masilamani, T.J., Loiselle, J.J., Sutherland, L.C., 2014. Assessment of reference genes for real-time quantitative PCR gene expression normalization during $\mathrm{C} 2 \mathrm{C} 12$ and $\mathrm{H} 9 \mathrm{c} 2$ skeletal muscle differentiation. Mol. Biotechnol. 56, 329-339.

Nakamura, T., Reicher, H., Sattler, W., 1998. Comparison of RRR- $\alpha$-and all-rac- $\alpha$-tocopherol uptake by permanent rat skeletal muscle myoblasts (L6 cells): effects of exogenous lipoprotein lipase. Lipids. 33, 1001-1008.

Obunike, J.C., Edwards, I.J., Rumsey, S.C., Curtiss, L.K., Wagner, W.D., Deckelbaum, R.J., Goldberg, I.J., 1994. Cellular differences in lipoprotein lipase-mediated uptake of low-density lipoproteins. J. Biol. Chem. 269, 13129-13135.

Perk, J., De Backer, G., Gohlke, H., Graham, I., Reiner, Ž., Verschuren, M., Albus, C., Benlian, P., Boysen, G., Cifkova, R., 2012. European guidelines on cardiovascular disease prevention in clinical practice (version 2012). Eur. Heart J. 33, 1635-1701.

Procyshyn, R.M., Tsai, G., Wasan, K.M., 2003. The influence of dyslipidemia on the plasma protein and lipoprotein distribution of haloperidol. Eur. Neuropsychopharmacol. 13, 33-37.

Redgrave, T., Roberts, D., West, C., 1975. Separation of plasma lipoproteins by density-gradient ultracentrifugation. Anal. Biochem. 65, 42-49. 
Reiner, Ž., 2014. Resistance and intolerance to statins. Nutr. Metab. Cardiovasc. Dis. 24, 1057-1066.

Rumsey, S., Obunike, J., Arad, Y., Deckelbaum, R., Goldberg, I., 1992. Lipoprotein lipase-mediated uptake and degradation of low-density lipoproteins by fibroblasts and macrophages. J. Clin. Invest. 90, 1504-1512.

Sattler, W., Levak-Frank, S., Radner, H., Kostner, G.M., Zechner, R., 1996. Muscle-specific overexpression of lipoprotein lipase in transgenic mice results in increased $\alpha$-tocopherol levels in skeletal muscle. Biochem. J. 318, 15-19.

Schirris, T.J., Renkema, G.H., Ritschel, T., Voermans, N.C., Bilos, A., Van Engelen, B.G., Brandt, U., Koopman, W.J., Beyrath, J.D., Rodenburg, R.J., 2015. Statin-induced myopathy is associated with mitochondrial complex III inhibition. Cell Metab. 22, 399-407.

Simon, N., Dailly, E., Jolliet, P., Tillement, J.-P., Urien, S., 1997. pH dependent binding of ligands to serum lipoproteins. Pharm. Res. 14, 527-532.

Sinzinger, H., O'grady, J., 2004. Professional athletes suffering from familial hypercholesterolaemia rarely tolerate statin treatment because of muscular problems. Br. J. Clin. Pharmacol. 57, 525-528.

Skottheim, I.B., Gedde-Dahl, A., Hejazifar, S., Hoel, K., Asberg, A., 2008. Statin induced myotoxicity: the lactone forms are more potent than the acid forms in human skeletal muscle cells in vitro. Eur. J. Pharm. Sci. 33, 317-325.

Stone, N.J., Robinson, J.G., Lichtenstein, A.H., Merz, C.N.B., Blum, C.B., Eckel, R.H., Goldberg, A.C., Gordon, D., Levy, D., Lloyd-Jones, D.M., 2014. 2013 ACC/AHA guideline on the treatment of blood cholesterol to reduce atherosclerotic cardiovascular risk in adults: a report of the American College of Cardiology/American Heart Association Task Force on Practice Guidelines. J. Am. Coll. Cardiol. 63, 2889-2934.

Taha, D.A., De Moor, C.H., Barrett, D.A., Gershkovich, P., 2014. Translational insight into statin-induced muscle toxicity: from cell culture to clinical studies. Transl. Res. 164, 85-109.

Taha, D.A., De Moor, C.H., Barrett, D.A., Lee, J.B., Gandhi, R.D., Hoo, C.W., Gershkovich, P., 2016. The role of acid-base imbalance in statin-induced myotoxicity. Transl. Res. 174, 140-160.

Traber, M.G., Olivecrona, T., Kayden, H.J., 1985. Bovine milk lipoprotein lipase transfers tocopherol to human fibroblasts during triglyceride hydrolysis in vitro. J. Clin. Invest. 75, 1729-1734.

Tripathy, S., 2009. Extreme metabolic alkalosis in intensive care. Indian J. Crit. Care Med. 13, 217-220.

Wang, H., Eckel, R.H., 2009. Lipoprotein lipase: from gene to obesity. Am. J. Physiol. Endocrinol. Metab. 297, E271-E288. 
Wasan, K.M., Brocks, D.R., Lee, S.D., Sachs-Barrable, K., Thornton, S.J., 2008. Impact of lipoproteins on the biological activity and disposition of hydrophobic drugs: implications for drug discovery. Nat. Rev. Drug Discov. 7, 84-99.

Wasan, K.M., Cassidy, S.M., 1998. Role of plasma lipoproteins in modifying the biological activity of hydrophobic drugs. J. Pharm. Sci. 87, 411-424.

Wasan, K.M., Conklin, J.S., 1997. Enhanced amphotericin B nephrotoxicity in intensive care patients with elevated levels of low-density lipoprotein cholesterol. Clin. Infect. Dis. 24, 78-80.

Wathen, C.G., Starkey, I.R., 1986. Survival from extreme lactic and keto-acidosis in diabetes-mellitus. Scott. Med. J. 31, 243-244.

Winocour, P., Waise, A., Young, G., Moriarty, K., 1989. Severe, self-limiting lactic acidosis and rhabdomyolysis accompanying convulsions. Postgrad. Med. J. 65, 321-322.

Yeganeh, M.H., Mclachlan, A.J., 2002. In-vitro distribution of terbinafine in rat and human blood. J. Pharm. Pharmacol. 54, 277-281.

Yokoyama, M., Seo, T., Park, T., Yagyu, H., Hu, Y., Son, N.H., Augustus, A.S., Vikramadithyan, R.K., Ramakrishnan, R., Pulawa, L.K., 2007. Effects of lipoprotein lipase and statins on cholesterol uptake into heart and skeletal muscle. J. Lipid Res. 48, 646-655.

Zimmer, D., 2014. New US FDA draft guidance on bioanalytical method validation versus current FDA and EMA guidelines: chromatographic methods and ISR. Bioanalysis. 6, 13-19. 


\section{Figure legends}

Fig. 1. Association of statins with human chylomicrons at different $\mathrm{pH}$ levels. Only simvastatin lactone showed a considerable association with human chylomicrons while other statins (simvastatin hydroxy acid, pravastatin lactone and pravastatin hydroxy acid) did not showed a detectable association at any $\mathrm{pH}$ level. Results are presented as box and whiskers, $(\mathrm{n}=6)$. Data were analysed by one-way ANOVA followed by Tukey's post hoc test, $* * p<001$.

Fig. 2. Distribution of simvastatin lactone into different lipoprotein fractions from hyperlipidaemic and normolipidaemic plasma. Simvastatin lactone was incubated with hyperlipidaemic or normolipidaemic plasma at $37^{\circ} \mathrm{C}$ over physiological, acidic, and alkaline $\mathrm{pH}$ with constant mixing for $1 \mathrm{~h}$. Lipoprotein fractions were separated by density gradient ultracentrifugation and the total amount of simvastatin (both acid and lactone forms) recovered from each fraction were presented as percentage of the initial amount of simvastatin lactone applied into plasma samples. Data are presented as mean $\pm \mathrm{SE},(\mathrm{n}=5)$. Statistical analysis was performed by two-way ANOVA followed by Fisher's LSD post hoc test, ${ }^{*} p<0.05,{ }^{* *} p<001,{ }^{* * *} p<0.001$. Red straight lines denote differences in $\%$ of simvastatin recovered in lipoprotein fractions from hyperlipidaemic and normolipidaemic plasmas. Black arched lines denote differences in simvastatin association within individual lipoprotein fraction as a function of $\mathrm{pH}$ changes.

Fig. 3. Total simvastatin uptake by undifferentiated and differentiated $\mathrm{C} 2 \mathrm{C} 12$ cells overexpressing mLPL, hLPL, and control cells transfected with empty vector after $3 \mathrm{~h}$ of incubation with simvastatin either loaded into triglyceride-rich lipoproteins or applied directly in solution. Data are presented as mean $\pm \mathrm{SE},(\mathrm{n}=5)$. Statistical analysis was performed by two-way ANOVA followed by Fisher's LSD post hoc test, ${ }^{*} p<0.05,{ }^{* *} p<001,{ }^{* * *} p<0.001$. Red straight lines denote differences in simvastatin uptake between cells treated with SV-TRL and SV-Sol. Black arched lines denote differences in simvastatin uptake by cells maintained at different $\mathrm{pH}$. 
Fig. 4. Total simvastatin uptake by undifferentiated and differentiated $\mathrm{C} 2 \mathrm{C} 12$ cells overexpressing mLPL, hLPL, and control cells transfected with empty vector after $3 \mathrm{~h}$ of incubation with simvastatin either loaded into low-density lipoprotein fraction or applied directly in solution. Data are presented as mean $\pm \mathrm{SE},(\mathrm{n}=5)$. Statistical analysis was done by two-way ANOVA followed by Fisher's LSD post hoc test, ${ }^{*} p<0.05,{ }^{* *} p<001,{ }^{* * *} p<0.001$. Red straight lines denote differences in simvastatin uptake between cells treated with SV-LDL and SV-Sol. Black arched lines denote differences in simvastatin uptake by cells maintained at different $\mathrm{pH}$.

Fig. 5. Lipoprotein lipase activity in undifferentiated and differentiated $\mathrm{C} 2 \mathrm{C} 12$ cells overexpressing mLPL, hLPL, and control cells transfected with empty vector. Data are presented as mean $\pm \mathrm{SE}$, $(n=3)$. Statistical analysis was done by two-way ANOVA followed by Fisher's LSD post hoc test, $* * * p<0.001$.

Fig. 6. MTT assay of undifferentiated and differentiated C2C12 cells overexpressing mLPL, hLPL, and control cells transfected with empty vector following treatment with simvastatin either loaded into triglyceride-rich lipoproteins or applied directly in solution at different $\mathrm{pH}$. Data are presented as mean $\pm \mathrm{SE}$ of 3 experiments, 8 replicate per experiment. The $\mathrm{IC}_{50}$ values are listed on graphs, when applicable, and were derived by computing dose-response curves using a 4-parameter, variable slope fit in GraphPad Prism. Statistical analysis was performed by two-way ANOVA followed by Fisher's

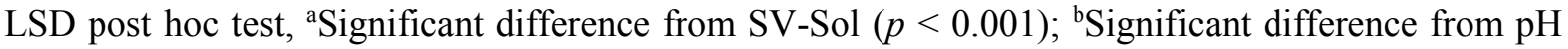
$7.4(p<0.001)$; ${ }^{\mathrm{c}}$ Significant difference from $\mathrm{pH} 7.4(p<0.01)$; ${ }^{\mathrm{d}}$ Significant difference from hLPL $(p<$

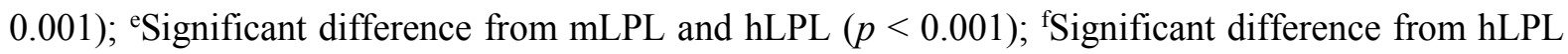
$(p<0.05)$.

Fig. 7. MTT assay of undifferentiated and differentiated C2C12 cells overexpressing mLPL, hLPL, and control cells transfected with empty vector following treatment with simvastatin either loaded into low-density lipoprotein fraction or applied directly in solution at different $\mathrm{pH}$. Data are presented as mean $\pm \mathrm{SE}$ of 3 experiments, 8 replicates per experiment. The $\mathrm{IC}_{50}$ values are listed on graphs, when 
applicable, and were derived by computing dose-response curves using a 4-parameter, variable slope fit in GraphPad Prism. Statistical analysis was done by two-way ANOVA followed by Fisher's LSD

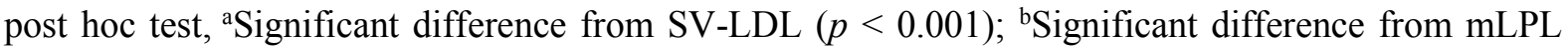
and hLPL $(p<0.001)$; ${ }^{\mathrm{c}}$ Significant difference from $\mathrm{pH} 7.4(p<0.001)$; ${ }^{\mathrm{d}}$ Significant difference from hLPL $(p<0.001)$; ${ }^{\text {eSignificant difference from } \mathrm{pH}} 7.4(p<0.01)$; ${ }^{\text {fSignificant difference from } \mathrm{mLPL}}$ $(p<0.001)$

Fig. 8. Lactate dehydrogenase release assay of undifferentiated and differentiated $\mathrm{C} 2 \mathrm{C} 12$ cells overexpressing mLPL, hLPL, and control cells transfected with empty vector following treatment with simvastatin either loaded into lipoprotein fractions or applied directly in solution at different $\mathrm{pH}$. Data are presented as mean $\pm \mathrm{SE},(n=6)$. Statistical analysis was performed by two-way ANOVA followed by Fisher's LSD post hoc test, ${ }^{*} p<0.05, * * p<001, * * * p<0.001$. Black arched lines denote differences in LDH release between different cell types. Red straight lines denote differences in LDH release from a single cell type maintained at different $\mathrm{pH}$. 


\section{Supplementary material}

\section{Hyperlipidaemia alone and in combination with acidosis can increase the incidence and severity of statin-induced myotoxicity}

Dhiaa A. Taha, ${ }^{a}$ Atheer Zgair, ${ }^{\mathrm{a}, \mathrm{b}}$ Jong Bong Lee, ${ }^{\mathrm{a}}$ Cornelia H. de Moor, ${ }^{\mathrm{c}}$ David A. Barrett, ${ }^{\mathrm{c}}$ Kimberley

D. Bruce, ${ }^{\mathrm{d}}$ Mitchell Sungelo, ${ }^{\mathrm{d}}$ Robert H. Eckel, ${ }^{\mathrm{d}}$ and Pavel Gershkovich ${ }^{\mathrm{a}}$

a Division of Medicinal Chemistry and Structural Biology, School of Pharmacy, University of Nottingham, Nottingham, UK.

${ }^{\mathrm{b}}$ College of Pharmacy, University of Anbar, Anbar, Iraq.

${ }^{\mathrm{c}}$ Division of Molecular and Cellular Science, School of Pharmacy, University of Nottingham, Nottingham, UK.

${ }^{d}$ Divisions of Endocrinology, Metabolism and Diabetes, Department of Medicine, University of Colorado Anschutz Medical Campus, Aurora, Colorado, USA. 
Supplementary Table 1. In silico prediction of statins association with chylomicrons.

\begin{tabular}{|c|c|c|c|c|c|}
\hline $\begin{array}{l}\text { Physicochemical } \\
\text { property }\end{array}$ & $\begin{array}{l}\text { Unscaled regression } \\
\text { coefficients }\end{array}$ & $\begin{array}{l}\text { Simvastatin } \\
\text { lactone }\end{array}$ & $\begin{array}{l}\text { Simvastatin } \\
\text { hydroxy acid }\end{array}$ & $\begin{array}{l}\text { Pravastatin } \\
\text { lactone }\end{array}$ & $\begin{array}{l}\text { Pravastatin } \\
\text { hydroxy acid }\end{array}$ \\
\hline $\log D_{7.4}$ & 0.299879 & 4.69 & 1.34 & 2.79 & -0.67 \\
\hline $\log P-\log D_{7.4}$ & -0.238127 & -0.27 & 2.72 & -1.08 & 2.02 \\
\hline PSA & -0.00855215 & 72.83 & 104.06 & 93.06 & 124.29 \\
\hline H-acceptors & -0.184359 & 5 & 6 & 6 & 7 \\
\hline FRB & 0.0805226 & 7 & 11 & 7 & 11 \\
\hline Density & 1.45337 & 1.11 & 1.13 & 1.18 & 1.21 \\
\hline Molar volume & 0.00545912 & 376.5 & 383.9 & 341.7 & 349.1 \\
\hline H-donors & 0.0823094 & 1 & 3 & 2 & 4 \\
\hline Constant & -5.24138 & & & & \\
\hline \multicolumn{2}{|c|}{$\begin{array}{l}\text { Predicted association with chylomicrons } \\
(\%)\end{array}$} & $9.08 \%$ & $0.24 \%$ & $1.78 \%$ & $0.04 \%$ \\
\hline
\end{tabular}

Abbreviations: $\log D$, distribution coefficient; $\log P$, partition coefficient; PSA, polar surface area; $\mathrm{H}$-acceptors, hydrogen-bond acceptors; FRB, freely rotatable bonds; H-donors, hydrogenbond donors. 

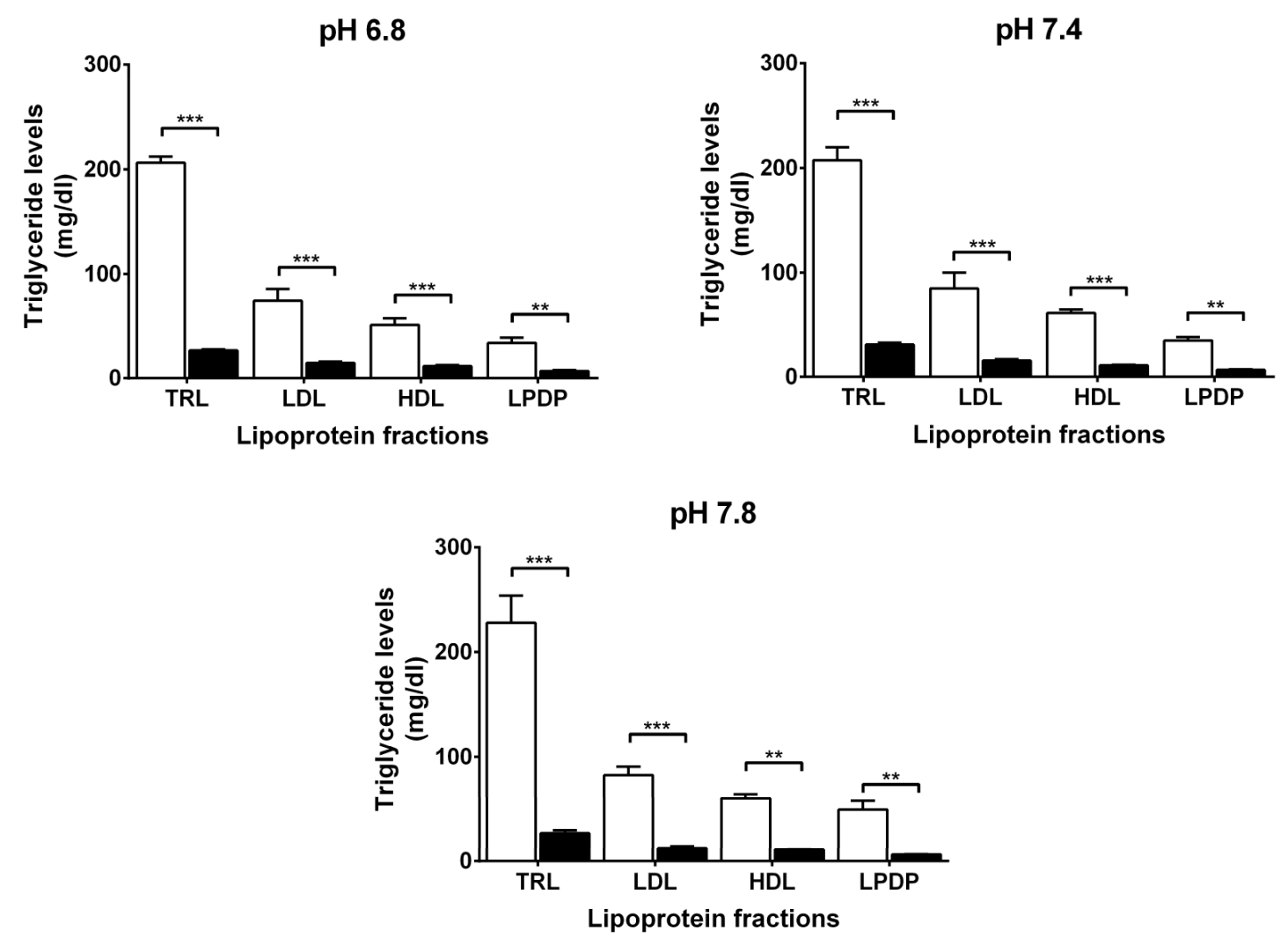

Hyperlipidaemic

Normolipidaemic

Supplementary Figure 1. Triglyceride content of individual lipoprotein fraction following ultracentrifugation of hyperlipidaemic and normolipidaemic plasma samples of different $\mathrm{pH}$. Results are expressed as mean $\pm \mathrm{SE}$, $(\mathrm{n}=5)$. Statistical analysis was done by two-way ANOVA followed by Fisher's LSD posthoc test, ${ }^{* *} p<001,{ }^{* * *} p<0.001$ 

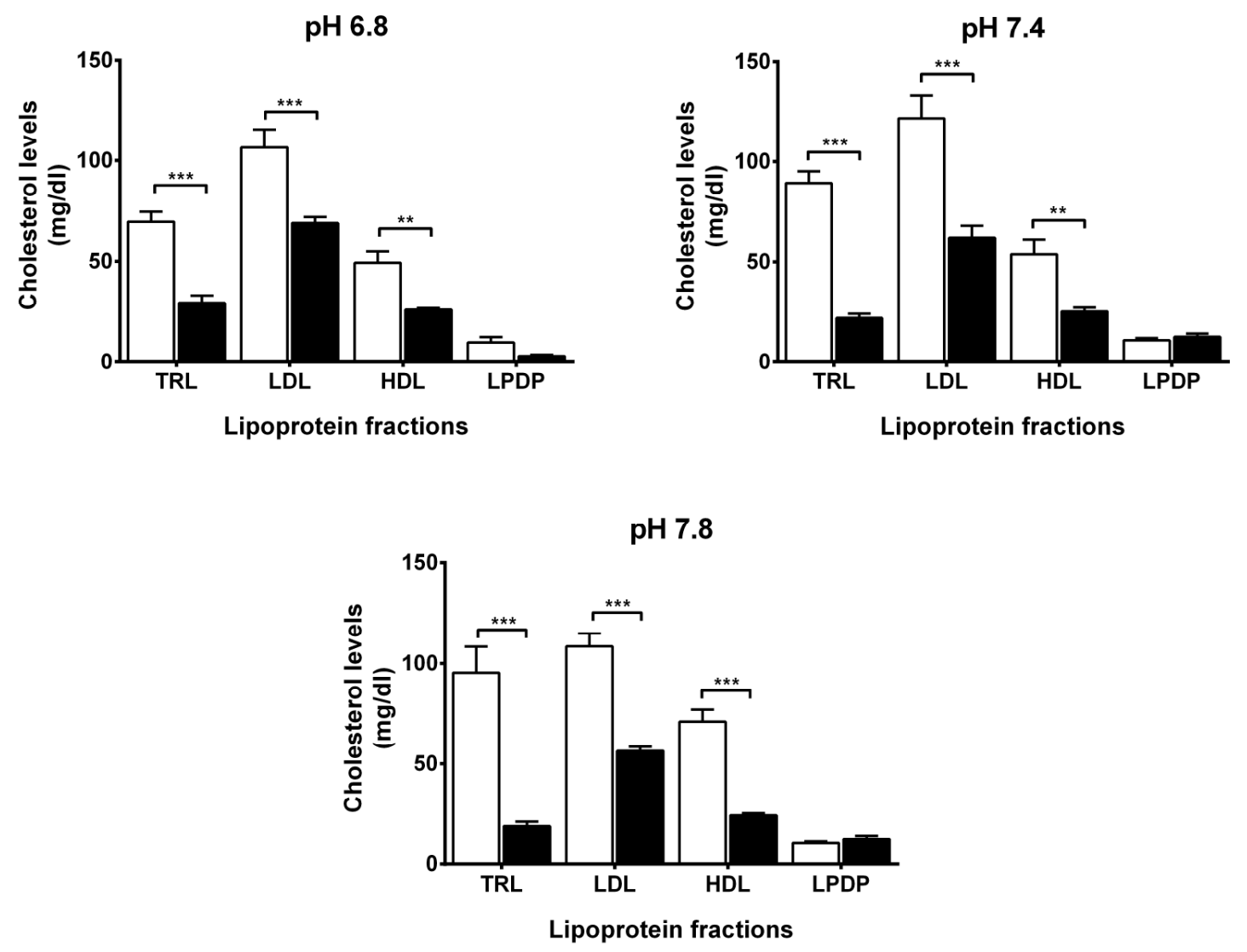

\section{Hyperlipidaemic}

Normolipidaemic

Supplementary Figure 2. Cholesterol content of individual lipoprotein fraction following ultracentrifugation of hyperlipidaemic and normolipidaemic plasma samples of different $\mathrm{pH}$. Results are expressed as mean $\pm \mathrm{SE}$, $(\mathrm{n}=5)$. Data were analysed by two-way ANOVA followed by Fisher's LSD posthoc test, $* * p<001, * * * p<0.001$. 

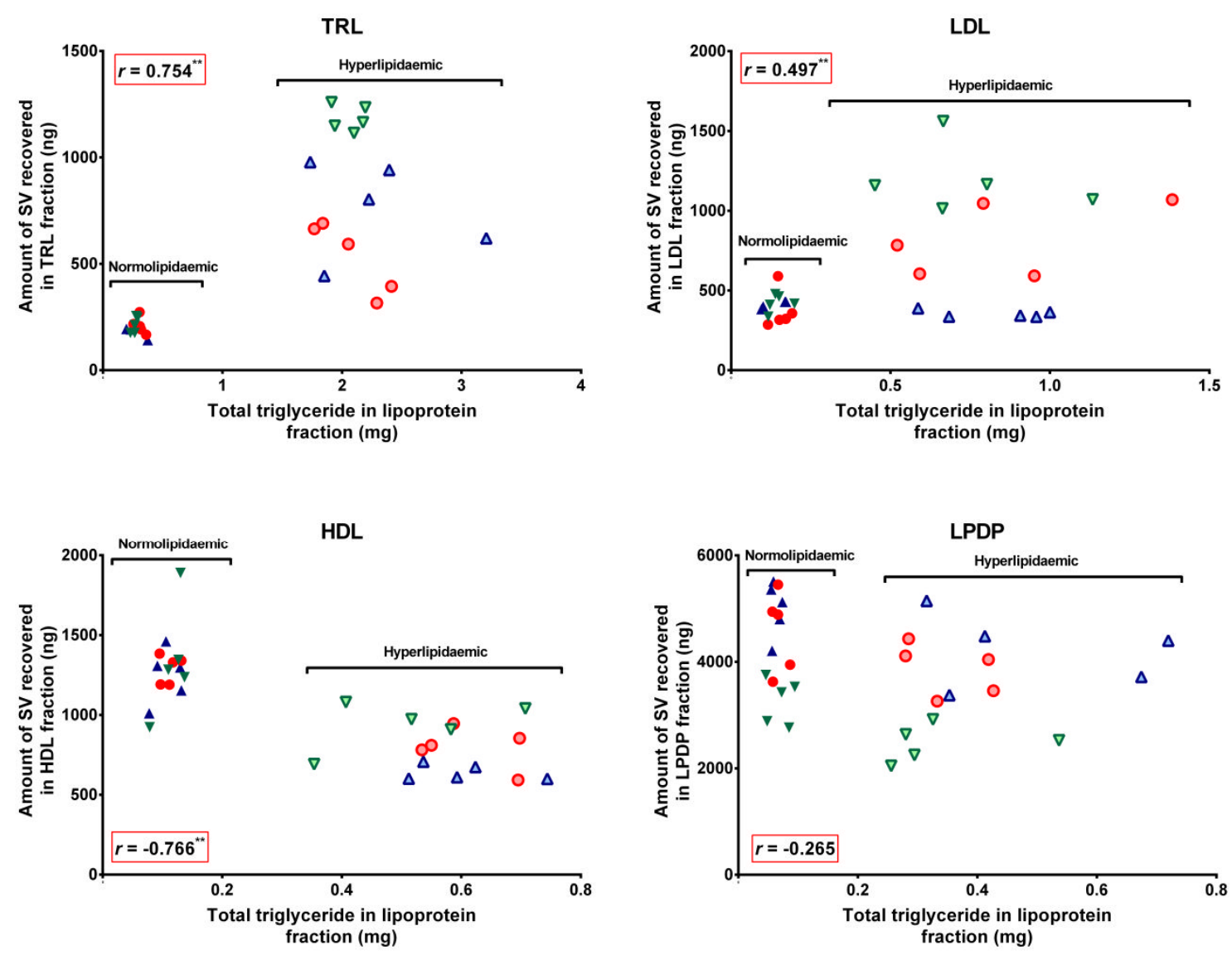

\begin{tabular}{|llllll|}
\hline$\nabla$ & $\mathrm{NL}, \mathrm{pH} 6.8$ & $\bullet$ & $\mathrm{NL}, \mathrm{pH} 7.4$ & $\Delta$ & $\mathrm{NL}, \mathrm{pH} 7.8$ \\
$\nabla$ & $\mathrm{HL}, \mathrm{pH} 6.8$ & $\circ$ & $\mathrm{HL}, \mathrm{pH} 7.4$ & $\Delta$ & $\mathrm{HL}, \mathrm{pH} 7.8$ \\
\hline
\end{tabular}

Supplementary Figure 3. Correlation between the amount of simvastatin (SV) recovered from individual lipoprotein fraction and the triglyceride content of the lipoprotein following incubation of hyperlipidaemic (HL) and normolipidaemic (NL) plasma of different $\mathrm{pH}$ with simvastatin lactone. Correlation was determined by Pearson's correlation coefficient (r), ${ }^{* *} p<0.01$. 
TRL
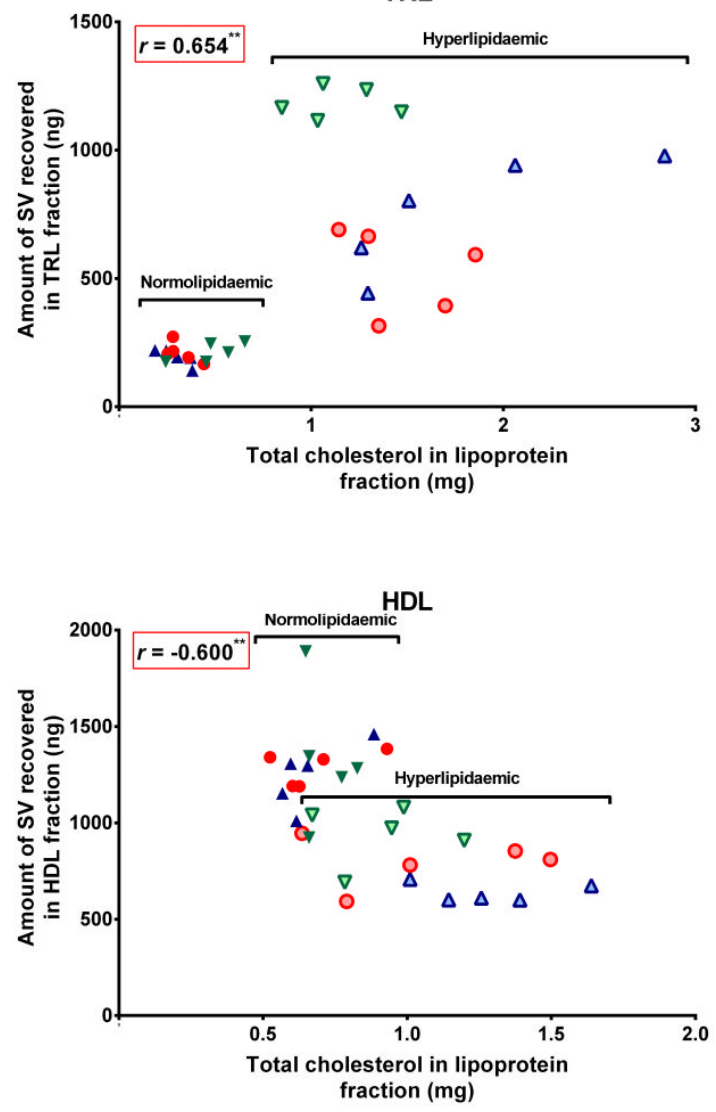

LDL
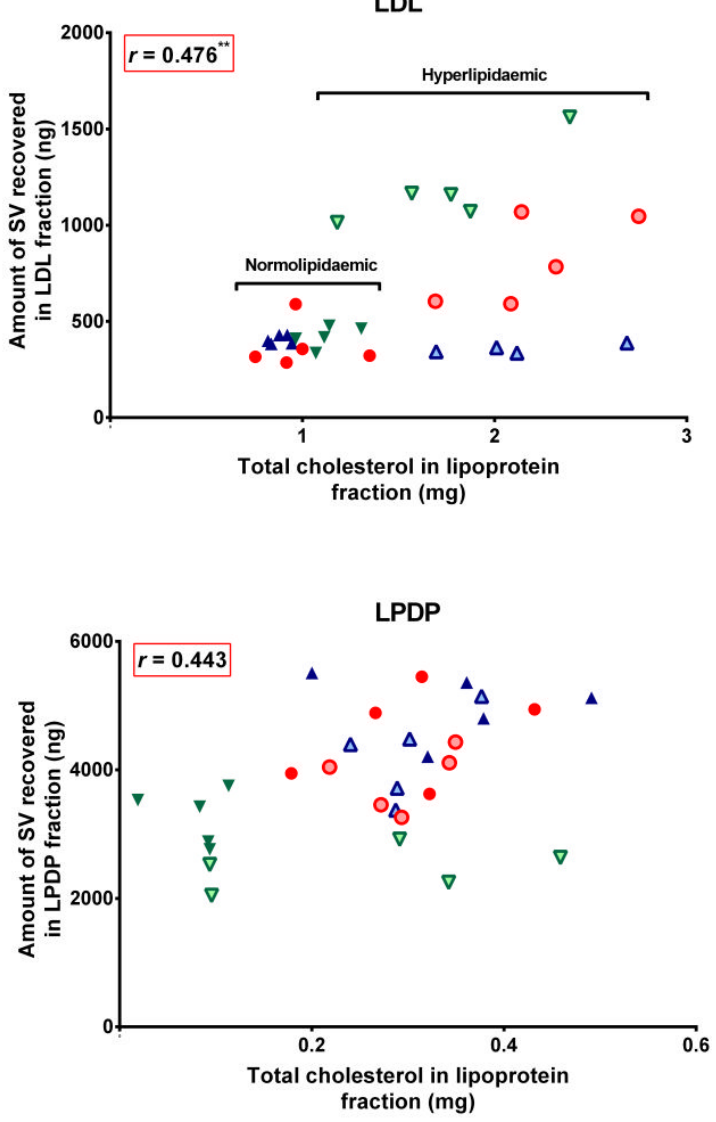

\begin{tabular}{|llllll|}
$\nabla$ & $\mathrm{NL}, \mathrm{pH} 6.8$ & $\bullet$ & $\mathrm{NL}, \mathrm{pH} 7.4$ & $\Delta$ & $\mathrm{NL}, \mathrm{pH} 7.8$ \\
$\nabla$ & $\mathrm{HL}, \mathrm{pH} 6.8$ & $\circ$ & $\mathrm{HL}, \mathrm{pH} 7.4$ & $\triangle$ & $\mathrm{HL}, \mathrm{pH} 7.8$ \\
\hline
\end{tabular}

Supplementary Figure 4. Correlation between the amount of simvastatin (SV) recovered from individual lipoprotein fraction and the cholesterol content of the lipoprotein following incubation of hyperlipidaemic (HL) and normolipidaemic (NL) plasma of different $\mathrm{pH}$ with simvastatin lactone. Correlation was determined by Pearson's correlation coefficient (r), ${ }^{* *} p<0.01$. 
TRL

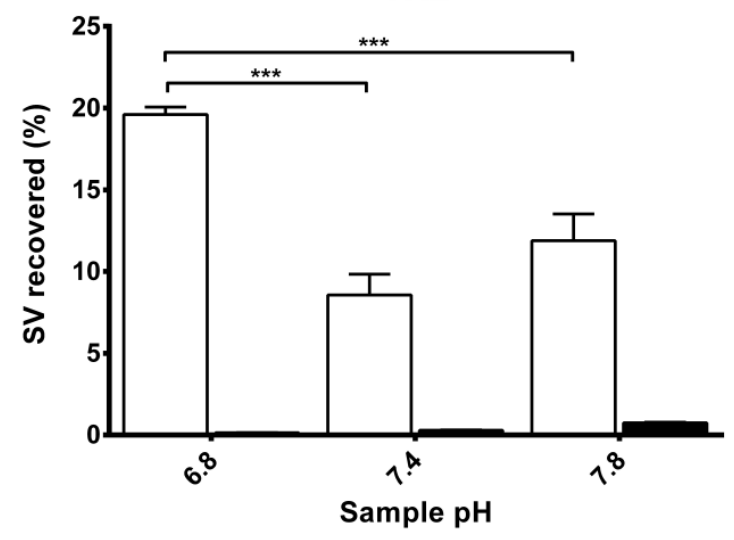

HDL

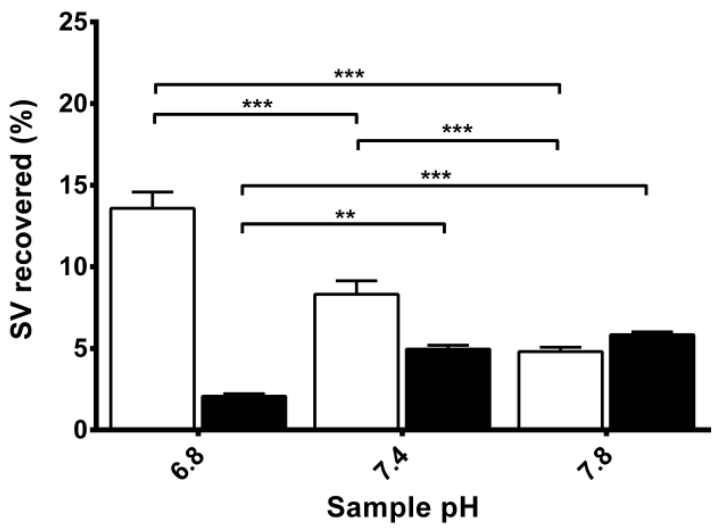

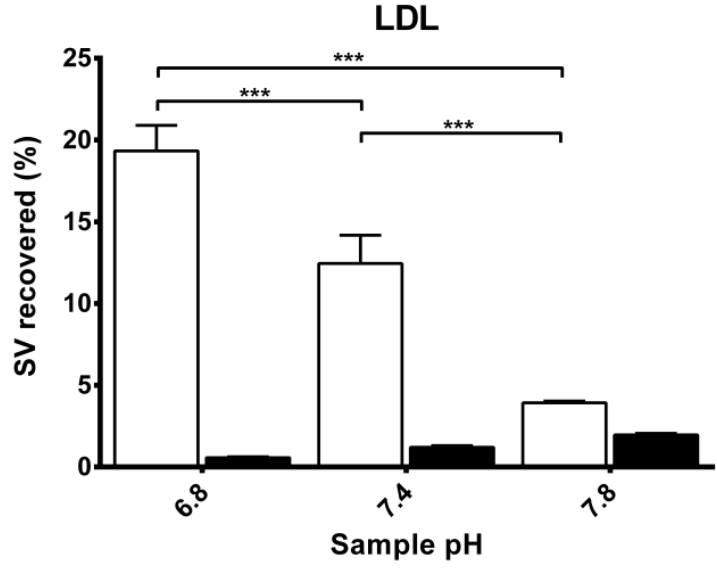

LPDP

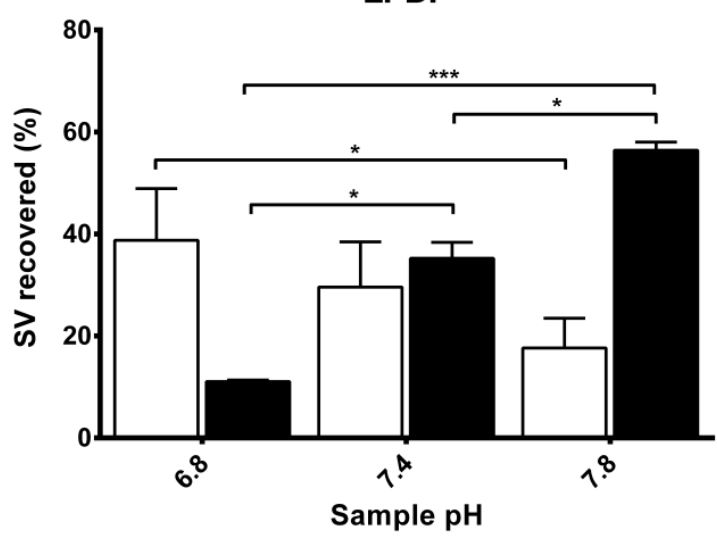

SVL

SVA

Supplementary Figure 5. Percentage of simvastatin lactone (SVL) and corresponding hydroxy acid form (SVA) recovered from individual lipoprotein fraction of hyperlipidaemic plasma. Results are expressed as mean $\pm \mathrm{SE}$, $(\mathrm{n}=5)$. Statistical analysis was done by two-way ANOVA followed by Fisher's LSD posthoc test, ${ }^{*} p<0.05, * * p<001, * * * p<0.001$. 
TRL

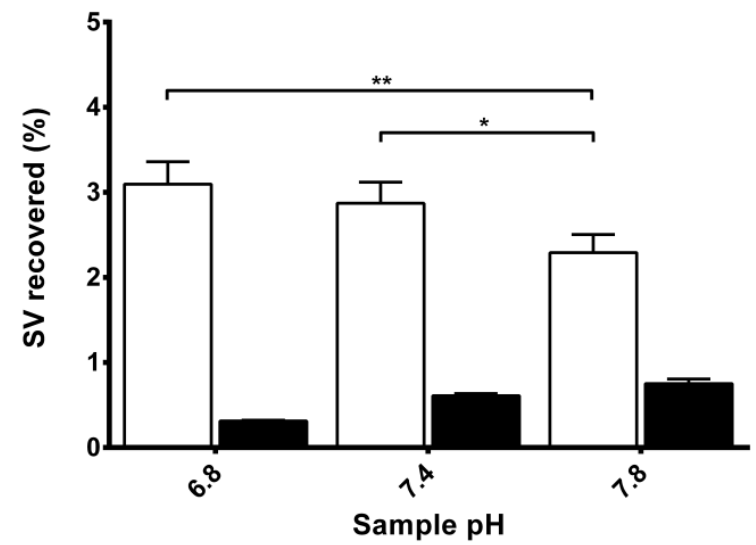

HDL

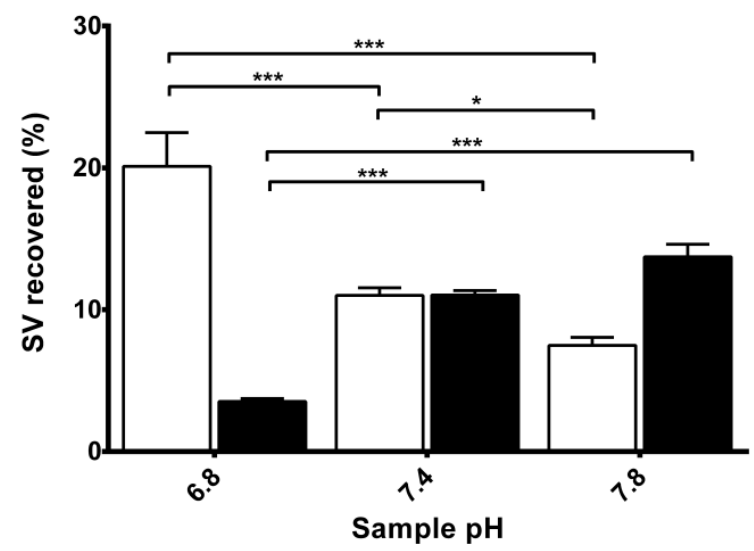

LDL
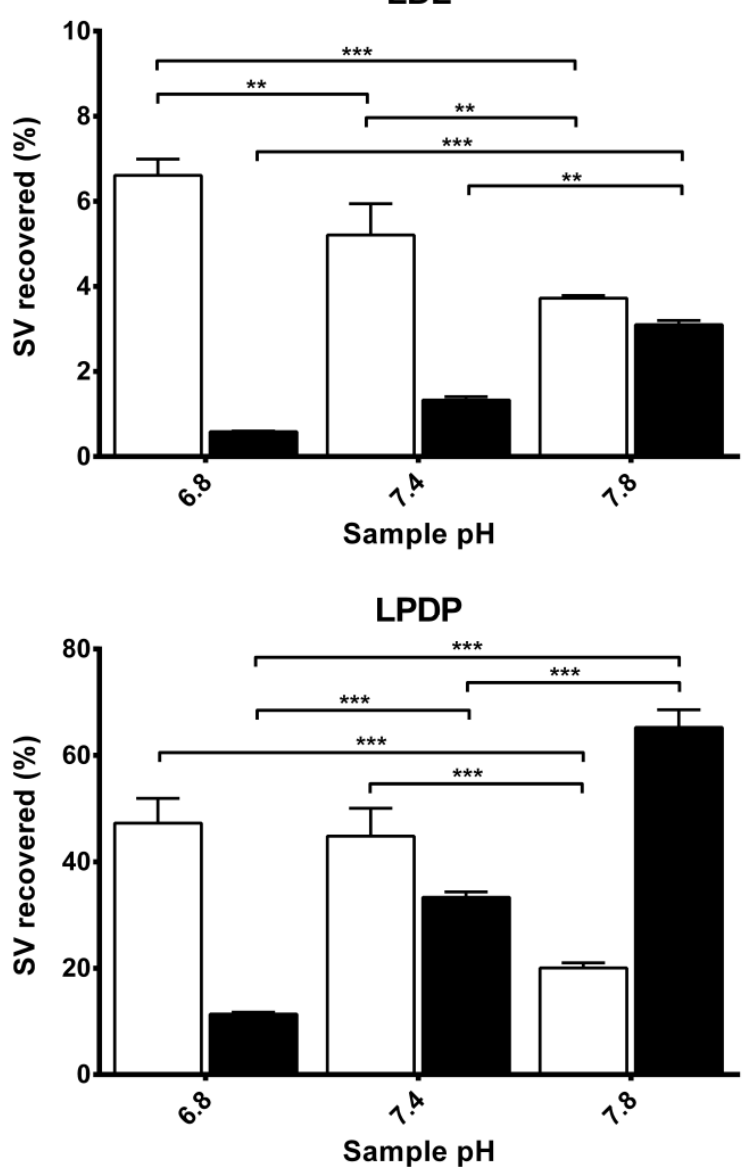

SVL

SVA

Supplementary Figure 6. Percentage of simvastatin lactone (SVL) and corresponding hydroxy acid form (SVA) recovered from individual lipoprotein fraction of normolipidaemic plasma. Results are expressed as mean $\pm \mathrm{SE}$, $(\mathrm{n}=5)$. Statistical analysis was done by two-way ANOVA followed by Fisher's LSD posthoc test, ${ }^{*} p<0.05,{ }^{*} p<001,{ }^{* * *} p<0.001$. 

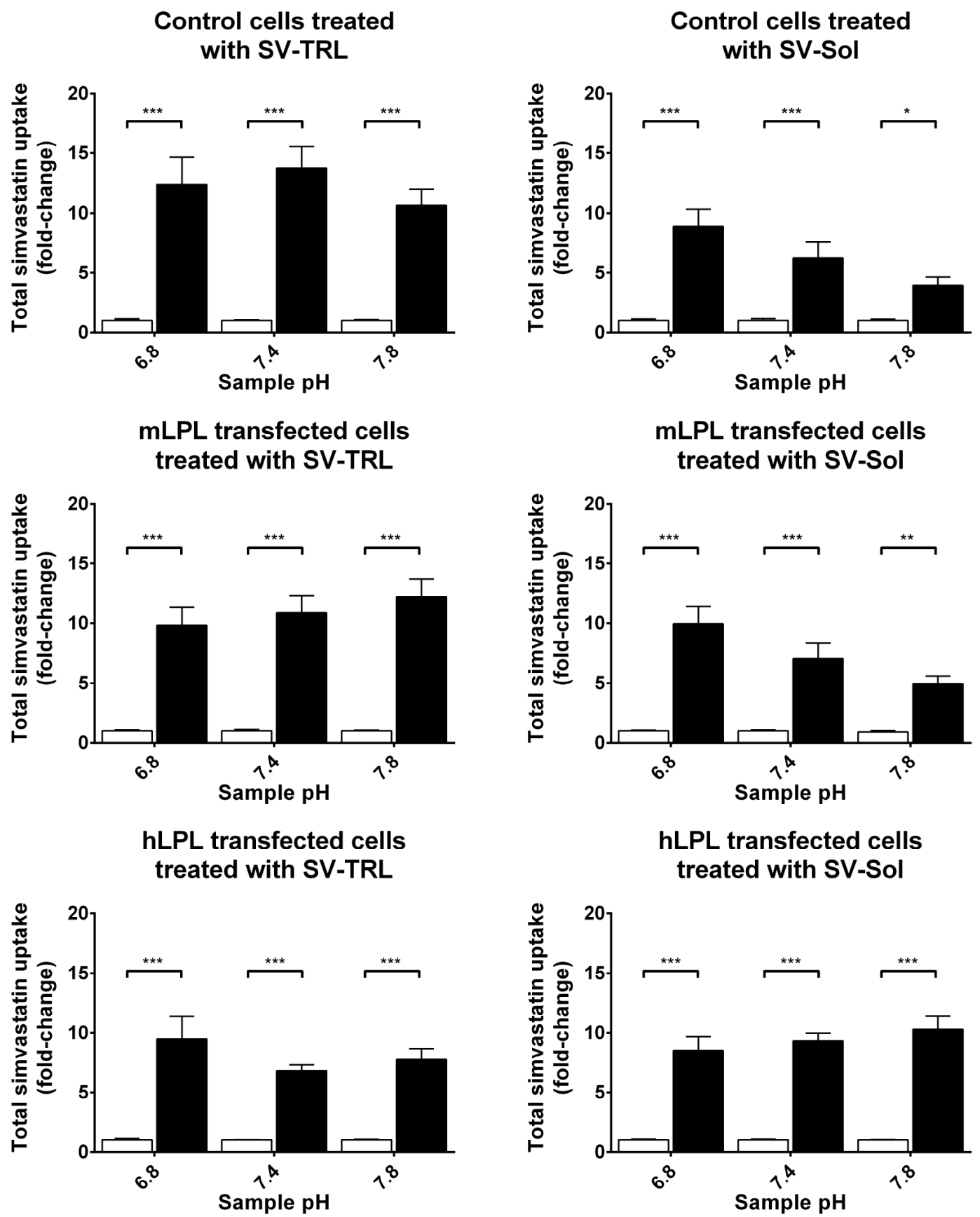
hLPL transfected cells treated with SV-Sol

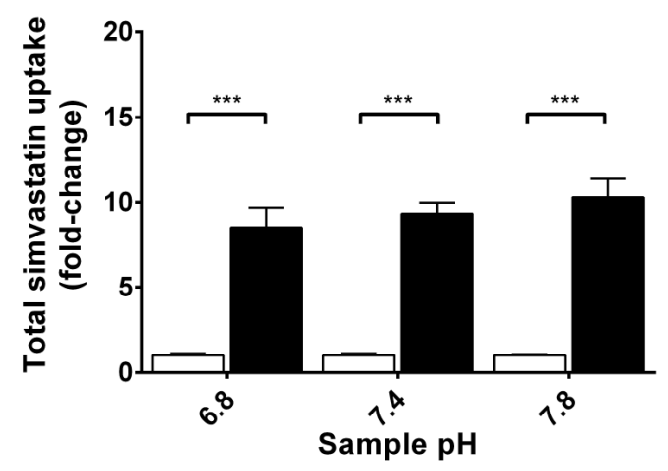

\section{Undifferentiated cells}

Differentiated cells

Supplementary Figure 7. Fold-change of total simvastatin uptake by undifferentiated and differentiated C2C12 cells overexpressing mLPL, hLPL, and control cells transfected with empty vector after $3 \mathrm{~h}$ of incubation with simvastatin either loaded into triglyceride-rich lipoproteins (SVTRL) or applied directly in solution (SV-Sol). Data are presented as mean $\pm \mathrm{SE},(n=5)$. Statistical analysis was performed by two-way ANOVA followed by Fisher's LSD post hoc test, ${ }^{*} p<0.05,{ }^{* *} p$ $<001, * * * p<0.001$. 

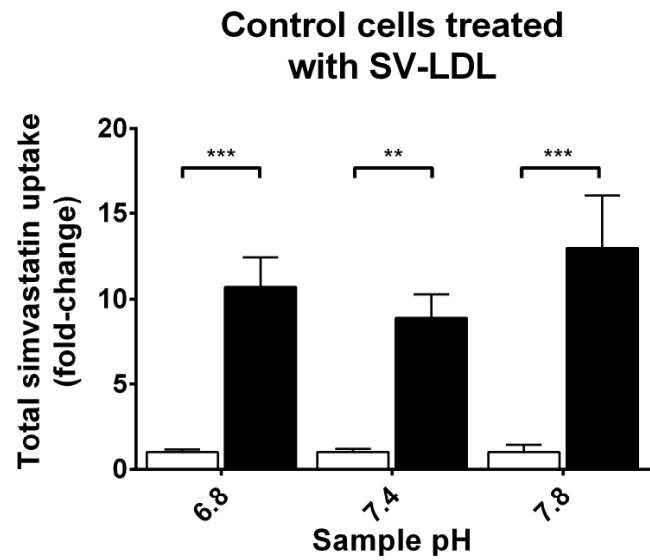

mLPL transfected cells treated with SV-LDL

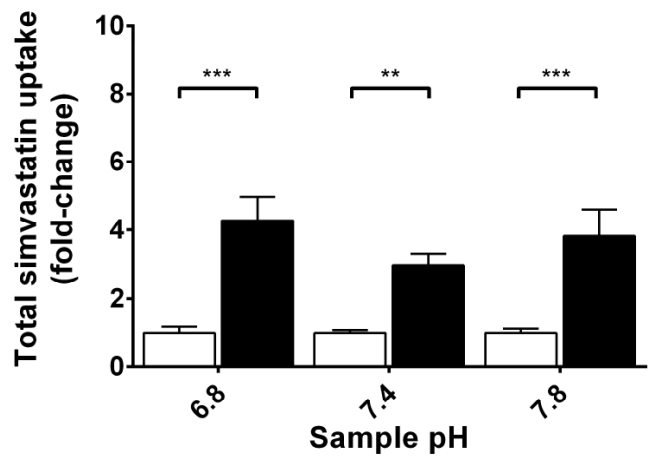

hLPL transfected cells treated with SV-LDL

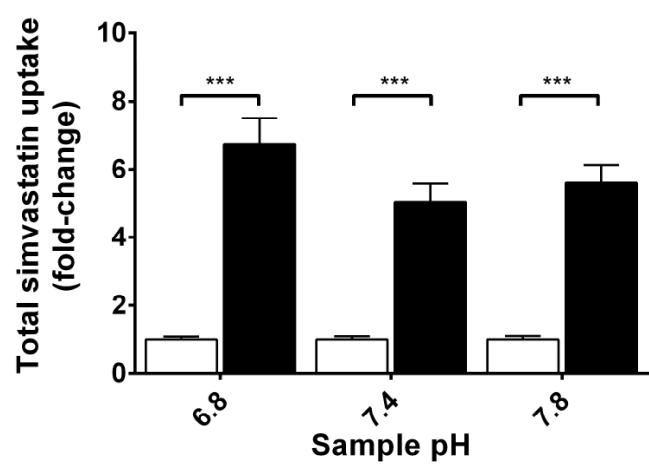

Control cells treated with SV-Sol

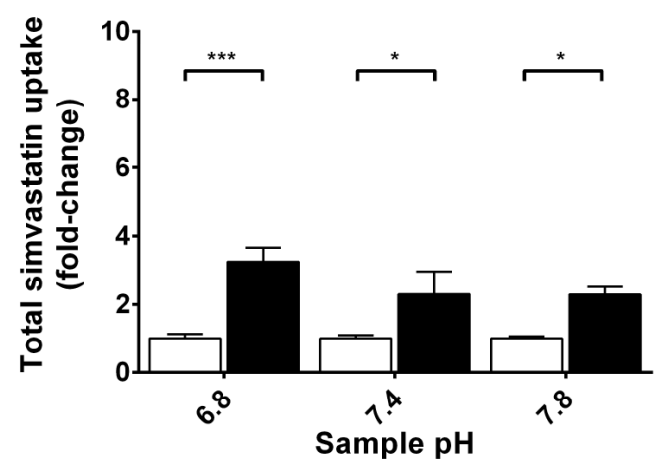

mLPL transfected cells treated with SV-Sol

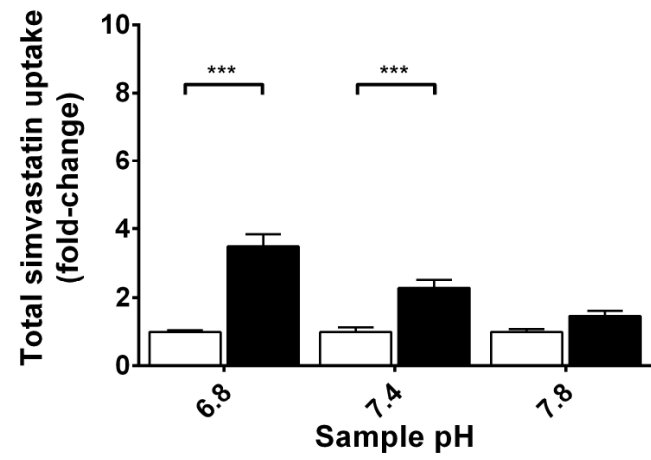

hLPL transfected cells treated with SV-Sol

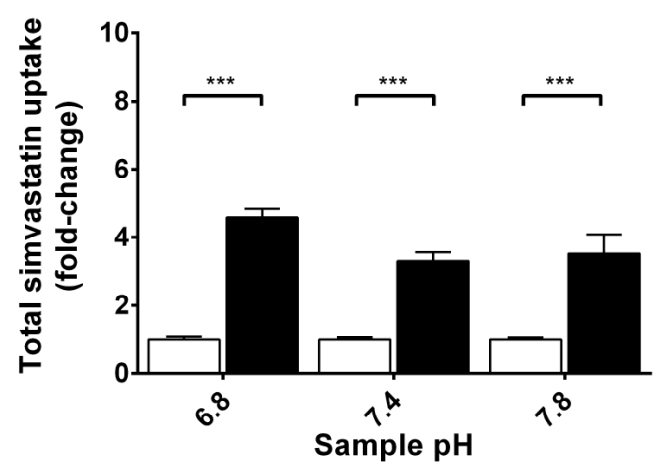

\section{$\square$ Undifferentiated cells $\quad$ Differentiated cells}

Supplementary Figure 8. Fold-change of total simvastatin uptake by undifferentiated and differentiated $\mathrm{C} 2 \mathrm{C} 12$ cells overexpressing mLPL, hLPL, and control cells transfected with empty vector after $3 \mathrm{~h}$ of incubation with simvastatin either loaded into low-density lipoprotein fraction (SVLDL) or applied directly in solution (SV-Sol). Data are presented as mean $\pm \mathrm{SE},(n=5)$. Statistical analysis was performed by two-way ANOVA followed by Fisher's LSD post hoc test, ${ }^{*} p<0.05, * * p$ $<001, * * * p<0.001$. 

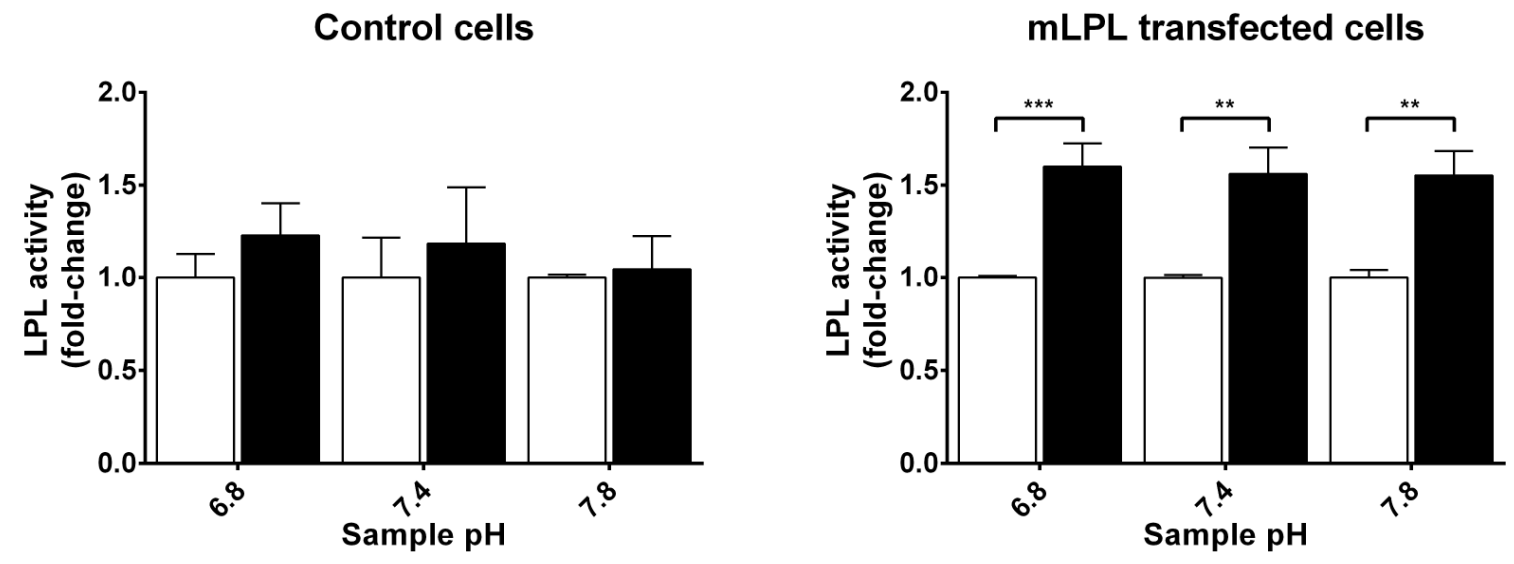

hLPL transfected cells

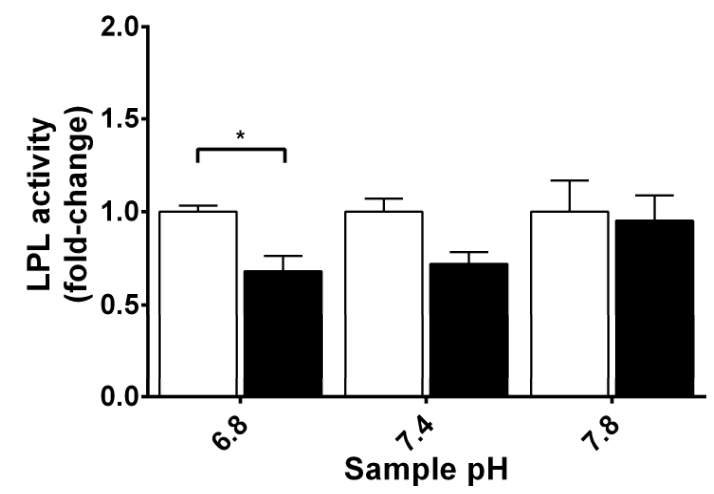

Undifferentiated cells

Differentiated cells

Supplementary Figure 9. Fold-change of lipoprotein lipase activity in undifferentiated and differentiated $\mathrm{C} 2 \mathrm{C} 12$ cells overexpressing $\mathrm{mLPL}$, hLPL, and control cells transfected with empty vector. Data are presented as mean $\pm \mathrm{SE},(\mathrm{n}=3)$. Statistical analysis was done by two-way ANOVA followed by Fisher's LSD post hoc test, ${ }^{*} p<0.05,{ }^{* *} p<001,{ }^{* * *} p<0.001$. 